\title{
O GOVERNO ESTADUAL NA EXPERIÊNCIA POLÍTICA BRASILEIRA: OS DESEMPENHOS LEGISLATIVOS DAS ASSEMBLÉIAS ESTADUAIS
}

\author{
Fabrício Ricardo de Limas Tomio
}

Paolo Ricci

\begin{abstract}
RESUMO
Este artigo analisa o volume e a dinamica da produção legislativa em 12 assembléias legislativas estaduais brasileiras durante duas legislaturas, 1999-2002 e 2002-2006. Em primeiro lugar, constatamos que a dinâmica legislativa das assembléias estaduais depende dos recursos institucionais conferidos constitucionalmente aos atores políticos pela Carta de 1988 que restringe a legislação proposta pelos deputados estaduais e limita a autonomia legislativa do Governador. Apesar de indícios claros da existência de uma dinâmica partidária relevante e um jogo efetivo entre governo e oposição nas assembléias que explica as variações encontradas entre os estados. Em segundo lugar, sinalizamos uma dinâmica legislativa estadual diversificada que não se restringe ao predominio do poder executivo. O volume de propostas apresentadas pelos deputados estaduais que não distribuem beneficios concentrados sinaliza para uma agenda pelo menos "desejada", principalmente direcionada a definir normas e diretrizes das políticas públicas estaduais. Por outro lado, é evidente que o sucesso legislativo dos deputados estaduais é elevado se comparado ao dos deputados federais, mas basicamente restrito a uma categoria de norma: a concessão de benefícios concentrados, destacando-se a categoria das declarações de utilidades públicas. O esforço de pesquisa aqui empreendido e os dados apresentados chamam a atenção para a necessidade de futuras pesquisas sobre as assembléias estaduais em busca de uma melhor compreensão do funcionamento das instituições brasileiras no âmbito subnacional.
\end{abstract}

PALAVRAS-CHAVE: processo legislativo; Assembléia Legislativa; relações Executivo-Legislativo; instituições políticas.

\section{INTRODUÇÃO}

O estudo das instituições representativas brasileiras tem levantado o interesse de pesquisadores de várias áreas. O Congresso Nacional é, hoje, sem sombra de dúvida, uma das instituições mais estudadas pelos cientistas políticos. Iniciou-se um processo de investigação que levou vários analistas, nacionais e estrangeiros, a estudá-lo sob ópticas diferentes e a partir de perspectivas teóricas às vezes contrapostas. Tudo considerado, porém, não há como escapar da seguinte constatação: pouco foi feito para o estudo das instituições representativas no âmbito subnacional. O interesse diversificado que encontramos na literatura especializada no que tange ao exame do Congresso Nacional, sobretudo da Câmara dos Deputados, ficou restrito a esse âmbito, manifestando, assim, um claro desvio de atenção para a compreensão das instituições de nível estadual e municipal. Quando se trata das assembléias legislativas estaduais, o mapeamento da literatura restringe-se a dois textos que, por serem os únicos, tornaram-se referência entre os estudiosos. Trata-se do livro de Fernando Luiz Abrucio (1998), Os barões da federação: os governadores e a redemocratização brasileira e a coletânea organizada por Fabiano Santos, em 2001, o poder legislativo nos Estados: diversidade e convergência (SANTOS, 2001b).

A constatação da incipiência dos estudos sobreas assembléias estaduais incentivou-nos a estender o debate sobre o Congresso Nacional a essas instituições. A nosso ver, os parlamentos estaduais não são versões em miniatura do poder legislativo federal. Há uma agenda política e uma pauta decisória própria dos estados. Por conta 
delas, os governos subnacionais encerrariam uma peculiaridade própria com respeito à suas respectivas dinâmicas decisórias, abrindo espaço para um exame mais sólido e abrangente de seus desempenhos. Este artigo é uma tentativa de seguir nesse sentido. Adotando uma abordagem comparativa, o exercício analítico aqui proposto foi centrado na sistematização dos achados de uma pesquisa mais abrangente sobre o funcionamento e desempenho de 12 assembléias legislativas. Estudos comparativos sobre tais esferas de poder são raros, como poucos e fragmentários ainda são os trabalhos monográficos disponíveis. No caso específico deste artigo, detemo-nos sobre o processo de formação e aprovação de projetos de leis estaduais, envolvendo as relações entre os poderes Executivo e Legislativo ${ }^{1}$. A decisão de privilegiar esse aspecto é compreensível quando são feitas pelo menos duas ponderações.

Em primeiro lugar, por tratar-se de tema central para dimensionar o papel dos executivos e dos legislativos estaduais. Os desempenhos legislativos das assembléias estaduais oferecernos-ão um indicativo claro da agenda prevalecente no âmbito subnacional. Sabemos que o Congresso Nacional não se distancia muito dos demais parlamentos do mundo em que prevalece a regra dos 90\% (LIMONGI, 2006), isto é, o governo é responsável por pelo menos $90 \%$ das propostas aprovadas e, ao mesmo tempo, a taxa de sucesso das propostas do governo alcança esse nível (LOEWENBERG \& PATTERSON, 1979). A questão agora é saber se isso se repete no âmbito subnacional. Os achados do texto organizado por Fabiano Santos (2001b) e as reflexões produzidas no trabalho seminal de Abrucio (1998) já haviam mostrado a presença de diferenças substantivas entre as assembléias legislativas, assim como um desempenho diferente entre elas e o Congresso Nacional. O fato de possuirmos agora informações consolidadas sobre a produção legislativa de 12 assembléias

\footnotetext{
1 Pode-se dizer que esse tema parece ser pouco explorado também em outros países. Basta citar, a título de exemplo, o caso americano. Em trabalho recente Gamm e Kousser (2010) apontam para a dificuldade de acesso às informações para o âmbito subnacional e oferecem a primeira análise sistemática da legislação em 13 estados durante 120 anos.
}

legislativas tornará certamente mais consistente um possível diagnóstico em tal sentido e, em última instância, permitir uma análise agregada e quantitativa do grau e da natureza da participação dos diferentes atores no processo decisório no âmbito subnacional.

A segunda razão pela qual escolhemos focar o estudo da produção legislativa reside no fato de que essa é uma das dimensões centrais consideradas pelos dois textos acima citados, que buscam enquadrar a dinâmica interna às assembléias estaduais. $\mathrm{Na}$ sua tentativa de elaborar um quadro compreensivo do sistema de governo que vigora nos estados, Fernando Abrucio cunha o termo "ultrapresidencialismo" para caracterizar a força dos governadores. Ao analisar 15 estados da federação na legislatura 1991-1994, o autor ressaltava o poder concentrado nas mãos dos governadores. Isso se refletia no modus operandi da relação entre poderes executivos e legislativos estaduais que, em termos de produção legislativa, como no caso de São Paulo, caracterizava-se pelo fato de que a legislação de cunho relevante passava unicamente pelo crivo do Governador, enquanto as assembléias discutiam e aprovavam questões secundárias. Já no livro organizado por Fabiano Santos (2001b), os autores que colaboraram na coletânea investigaram seis estados durante a legislatura 1995-1998 chegando a conclusões diversas e convergentes sobre a predominância do poder Executivo no processo legislativo estadual identificando maior equilíbrio entre os poderes Legislativo e o Executivo nos estados do Rio de Janeiro e Minas Gerais, enfatizando o caráter autônomo das assembléias locais; observando a grande capacidade governativa dos poderes executivos no Rio Grande do Sul e Ceará, resultante de maiorias partidárias estáveis produto de alianças eleitorais; a presença do "ultrapresidencialismo" nos estados de São Paulo e Espírito Santo. Após mais de uma década de distância é lícito empreender uma análise que possa averiguar se predomina o caráter "ultrapresidencial" ou o equilíbrio entre o poder Legislativo e o Executivo na dinâmica decisória das assembléias estaduais.

O texto é organizado da seguinte forma. Nas duas seções seguintes buscamos dimensionar o volume e a dinâmica da produção legislativa em 12 estados, durante duas legislaturas seguidas (1999- 
2002 e 2002-2006) $)^{2}$. Identificar alguns aspectos determinantes do processo decisório estadual é o objetivo central dessas seções. Para isso, a análise fundamenta-se na exploração dos dados a partir de alguns indicadores como o volume dos projetos apresentados, a taxa de sucesso e os vetos apontados pelo poder executivo. Em outra seção discutimos o problema referente ao conteúdo das propostas apresentadas pelos governos e deputados estaduais. Nossa intenção, aqui, é problematizar o processo legislativo estadual a partir do tipo de proposta em discussão. A nosso entender é esse aspecto que nos ajuda a compreender melhor a dinâmica legislativa e o desempenho dos legislativos estaduais. Por fim, concluímos sugerindo as etapas futuras de investigação para o estudo das assembléias estaduais.

II. A PRODUÇÃO LEGISLATIVA DE 12 ASSEMBLÉIAS LEGISLATIVAS.
Gostaríamos, de iniciar com uma comparação com a Câmara dos Deputados ${ }^{3}$. O exercício proposto, obviamente, não é meramente descritivo, mas visa dimensionar as diferenças entre os dois níveis institucionais, o nacional e o estadual. Dada a natureza do estudo, centrada sobre a produção legislativa, a questão principal é saber se estamos perante governos subnacionais com um formato da dinâmica legislativa diferente ou, caso contrário, similar à instância representativa de nível superior. Para isso detemonos sobre dois indicadores freqüentemente utilizados pela literatura para avaliar o desempenho legislativo de uma instituição: as taxas de dominância e as de sucesso legislativo. A Tabela 1 informa-nos a respeito desses dois indicadores levando em conta os resultados encontrados para as 12 assembléias estaduais e a Câmara dos Deputados nas duas experiências democráticas brasileiras, a democracia de 1946 e a atual.

TABELA 1 - COMPARAÇÃO DAS TAXAS DE DOMINÂNCIAE SUCESSO DAS PROPOSTAS ORIUNDAS DO EXECUTIVO E DO LEGISLATIVO (\%)

\begin{tabular}{|l|c|c|c|}
\hline $\begin{array}{l}\text { INSTITUIÇÃo } \\
\text { REPRESENTATIVA }\end{array}$ & $\begin{array}{c}\text { DOMINÂNCIA } \\
\text { DO EXECUTIVO NA } \\
\text { PRODUÇĂO LEGAL }\end{array}$ & $\begin{array}{c}\text { SUCESSO DO } \\
\text { EXECUTIVO }\end{array}$ & $\begin{array}{c}\text { SUCESSO DO } \\
\text { LEGISLATIVO }\end{array}$ \\
\hline $\begin{array}{l}\text { Assembléias legislativas } \\
\text { (1999-2006) } \\
\text { Câmara dos Deputados } \\
\text { (1947-1964) }\end{array}$ & 27,3 & 87,6 & 43,3 \\
$\begin{array}{l}\text { Câmara dos Deputados } \\
(1988-2007)\end{array}$ & 38,5 & 29,5 & 11,6 \\
\hline
\end{tabular}

FONTE: Banco de Dados Legislativos das Assembléias Estaduais. Para o período de 1988 a 2007, ver Figueiredo e Limongi (2007).

NOTAS:

1. O dado é uma estimativa feita a partir das informações fornecidas pelo portal da Câmara de Deputados.

2. A taxa de sucesso do poder Legislativo para o período 1947-1964 é calculada a partir de Braga (2008, p. 161, Tabela 3).

2 Para maiores detalhes sobre a coleta dos dados ver o Apêndice. No Apêndice discutimos também a possibilidade de viés de seleção da pesquisa e que deriva da constatação de que estamos tratando de apenas 12 estados e não de todas as assembléias estaduais.
3 Seguimos aqui a interpretação majoritária da literatura que avalia os desempenhos do Congresso Nacional destacando quase que unicamente o desempenho na Câmara dos Deputados. 
A dominância do poder Executivo indica-nos o percentual de projetos transformados em norma jurídica de iniciativa do Executivo. Nota-se que o percentual para as assembléias estaduais é similar àquele do Executivo durante o período 1947-1964, demonstrando baixa dominância. Isso indica certo ativismo legislativo por parte dos deputados estaduais que não se observa no âmbito federal durante a nossa primeira experiência democrática ou, dito de maneira mais direta, significa que a maioria dos outcomes legislativos é de origem parlamentar. Os dados sobre o sucesso dos poderes Executivo e Legislativo - referente à porcentagem de projetos apresentados e sancionados -, oferecem-nos informações para confirmar essa suposição. Por um lado, é incontestável o dado que configura o poder Executivo como ator bemsucedido, até percentualmente superior ao valor encontrado para a Câmara. Ao mesmo tempo, porém, e diferentemente da esfera federal de 1988 e do período democrático de 1946, os próprios deputados estaduais registram uma taxa de sucesso média consideravelmente elevada. Em síntese, os dados revelaram uma configuração dos desempenhos legislativos diferente da que encontramos no âmbito federal. Fato que, portanto, justifica e estimula ao mesmo tempo a investigação em torno do papel das assembléias estaduais ${ }^{4}$.

O objetivo desta seção é justamente oferecer um quadro detalhado para a produção legislativa das 12 assembléias estaduais. Quando possível continuaremos com a comparação com a Câmara, de modo a termos uma idéia mais nítida em torno do comportamento diferenciado entre as duas instâncias representativas. Partimos do estudo do volume da produção apresentada pelo poder executivo e o legislativo. O Gráfico 1 sintetiza essa informação, por estado.

GRÁFICO 1 - PROJETOS DE LEI APRESENTADOS POR ASSEMBLÉIA LEGISLATIVA, DIFERENCIANDO POR ORIGEM E LEGISLATURA (EM \%)

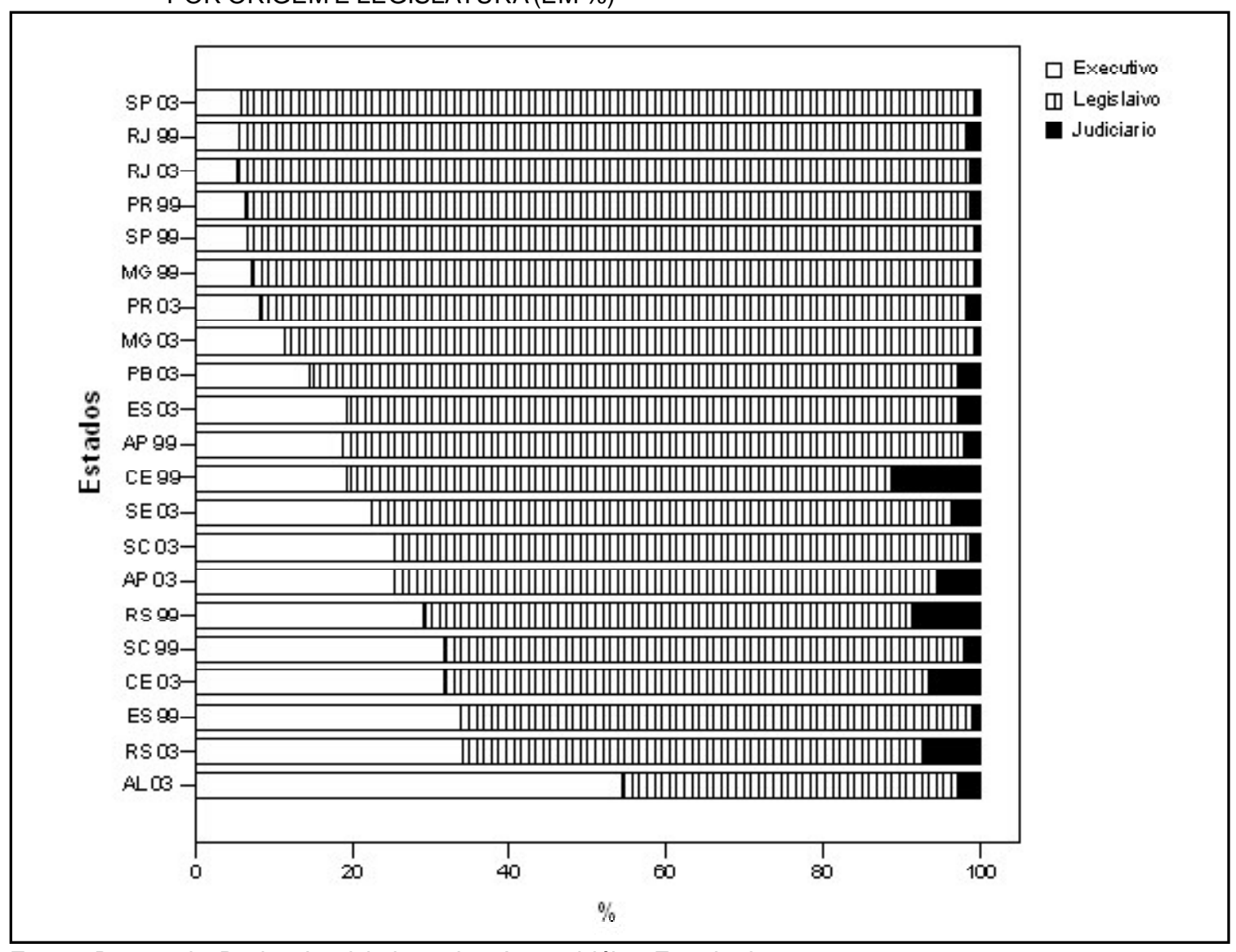

Fonte: Banco de Dados Legislativos das Assembléias Estaduais.

${ }^{4}$ A comparação entre Câmara dos Deputados e assembléias
estaduais pode ser criticada sob a alegação de que teria 
Interessa-nos, em particular, destacar o seguinte ponto. Observa-se que o volume das propostas apresentadas pelos deputados estaduais é elevado se comparado com o do poder Executivo e, sobretudo, que há grande oscilação entre as assembléias legislativas. Comparando a iniciativa do governo e a do poder Legislativo, percebe-se que a primeira é baixa em alguns casos (vê-se Rio de Janeiro, Paraná, São Paulo e Minas Gerais), relativamente baixa em outros (como Rio Grande do Sul, Santa Catarina e Espírito Santo) ou, excepcionalmente, tende a ser maior em Alagoas. Os dados confirmam o que já sabíamos para a Câmara dos Deputados, cujos parlamentares também apresentam número elevado de propostas legislativas. Entretanto, porque ocorre esse domínio do poder Legislativo em termos de propostas apresentadas? Do ponto de vista formal, considerando as regras que disciplinam a ação dos deputados durante o processo legislativo, apresentar um projeto não é uma ação altamente custosa. Em geral as regras que regem os trabalhos legislativos no Congresso Nacional, tais como aquelas das assembléias legislativas, são bastante permissivas nesse sentido. Certamente isso elucida o protagonismo legislativo dos deputados estaduais. A explanação para a variação encontrada entre as assembléias legislativas é imputável ao tamanho das assembléias. Por exemplo, na legislatura 19992002 os deputados amapaenses apresentaram 402 propostas legislativas e os mineiros 2417 projetos. Ou seja, os segundos foram seis vezes mais ativos que os representantes do Amapá. A

baixo alcance teórico, na medida em que as instituições representativas consideradas possuem características institucionais distintas. Entretanto, a nosso entender a comparação é válida. Para começar, ela permite-nos decifrar as diferenças entre as instâncias representativas em nível nacional e estadual. Essa constatação não é de pouca monta. Por exemplo, o dado peculiar relativo ao nível elevado de leis oriundas do poder Legislativo estadual destoa da experiência nacional e não deve ficar despercebido. Isso chama a atenção também para o problema mais geral do desempenho das assembléias legislativas e, em particular, para a questão da produção legislativa e de suas respectivas características. Dito de outra forma, o dado levanta uma questão teórica importante, relativa ao papel que os deputados estaduais possuem como atores políticos que produzem normas jurídicas. Esse aspecto é tão importante que lhe será dedicado uma seção à parte do artigo onde se buscará mapear o formato dessas normas de origem parlamentar. resposta para esse diferencial é, simplesmente, que as assembléias estaduais têm tamanhos diferentes. Há grande variação entre elas. A de São Paulo, por exemplo, compõe-se de 94 deputados, a do Rio de Janeiro tem 70 representantes enquanto a de Alagoas apenas $27 \mathrm{e}$ as de Sergipe e Amapá têm 245. Esse argumento é válido, porém, apenas para as propostas dos deputados. Quando se passa a considerar a produção legislativa do poder Executivo, o tamanho das assembléias nesse caso não é fator explicativo. Isso, claramente, sinaliza para um ativismo legislativo do poder Executivo estadual que deve ser melhor indagado, considerando outros fatores como a complexidade da administração pública estadual e a provisão constitucional em regulamentar seu funcionamento por decretos administrativos, o tamanho da coalizão governamental e o apoio encontrado pelo Governador na própria Assembléia.

Para entender melhor a dinâmica da produção legislativa, passamos agora ao estudo das propostas aprovadas. Inicialmente, comparamos a produção legislativa do poder Executivo com a do poder Legislativo. Da leitura dos dados apresentados no Gráfico 2 queremos destacar o seguinte ponto: no caso dos governos subnacionais observamos a presença de um volume de leis oriundas do poder Executivo bem inferior à do poder Legislativo, diferentemente do que ocorre no Congresso Nacional atual em que, de acordo com Figueiredo e Limongi (2007), o percentual de leis de iniciativa do poder Executivo foi de $83,3 \%$ entre 1988 e 2007. Com a exceção de Alagoas 2003 (AL03), Ceará 2003 (CE03), Rio Grande do Sul 1999 e 2003 (RS99 e RS03) e São Paulo 1999 (SP99), nas demais legislaturas a maioria das leis são oriundas do poder Legislativo. $\mathrm{O}$ dado revela que, na prática, as leis estaduais dos deputados têm peso significativo não apenas considerando-se o volume das propostas apresentadas, mas também na produção legislativa final. A Tabela 2, a seguir, confirma esse aspecto. Nela reportam-se as taxas de sucesso do governo e do poder legislativo por legislatura.

\footnotetext{
5 A correlação entre número de projetos dos deputados estaduais e tamanhos da assembléia é de 0,870 .
} 
TABELA 2 - TAXA DE SUCESSO DOS PROJETOS POR ESTADO E POR ORIGEM (\%)

\begin{tabular}{|l|c|c|c|}
\hline ESTADOS & EXECUTIVO & LEGISLATIVO & $\begin{array}{c}\text { JUDICIÁRIO E } \\
\text { OUTROS }\end{array}$ \\
\hline Alagoas 2003 & 91,7 & 43,3 & 80,0 \\
Amapá 1999 & 93,8 & 54,2 & 100,0 \\
Amapá 2003 & 91,9 & 57,6 & 87,5 \\
Ceará 1999 & 92,9 & 40,2 & 76,0 \\
Ceará 2003 & 95,5 & 37,8 & 82,3 \\
Espírito Santo 1999 & 85,4 & 57,3 & 84,6 \\
Espíito Santo 2003 & 95,0 & 55,9 & 88,1 \\
Minas Gerais 1999 & 67,4 & 54,0 & 81,3 \\
Miñâs Gêrāis 2003 & 74,1 & 51,8 & 63,3 \\
Paraíba 2003 & 97,0 & 57,8 & 88,1 \\
Paraná 1999 & 81,4 & 54,0 & 65,5 \\
Paraná 2003 & 91,4 & 50,5 & 78,6 \\
Rio de Janeiro 1999 & 78,0 & 23,2 & 93,9 \\
Rio de Janeíro 2003 & 82,7 & 21,2 & 83,7 \\
Rio Grande do Sul 1999 & 78,3 & 26,2 & 83,6 \\
Rio Grande do Sul 2003 & 91,1 & 27,2 & 74,6 \\
Santa Catarina 1999 & 91,9 & 59,9 & 77,8 \\
Santa Catarina 2003 & 93,6 & 72,5 & 91,3 \\
Sergipe 2003 & 98,4 & 97,1 & 98,3 \\
São Paulo 1999 & 75,3 & 24,6 & 79,0 \\
São Paulo 2003 & 79,6 & 43,6 & 78,3 \\
Total (assembléias legislativas\} & 87,6 & \\
\hline
\end{tabular}

FONTE: Banco de Dados Legislativos das Assembléias Estaduais. Para o período de 1988 a 2007, ver Figueiredo e Limongi (2007). NOTAS:

1. O dado é uma estimativa feita a partir das informações fornecidas pelo portal da Câmara de Deputados.

2. A taxa de sucesso do poder Legislativo para o período 1947-1964 é calculada a partir de Braga (2008, p. 161, Tabela 3). 


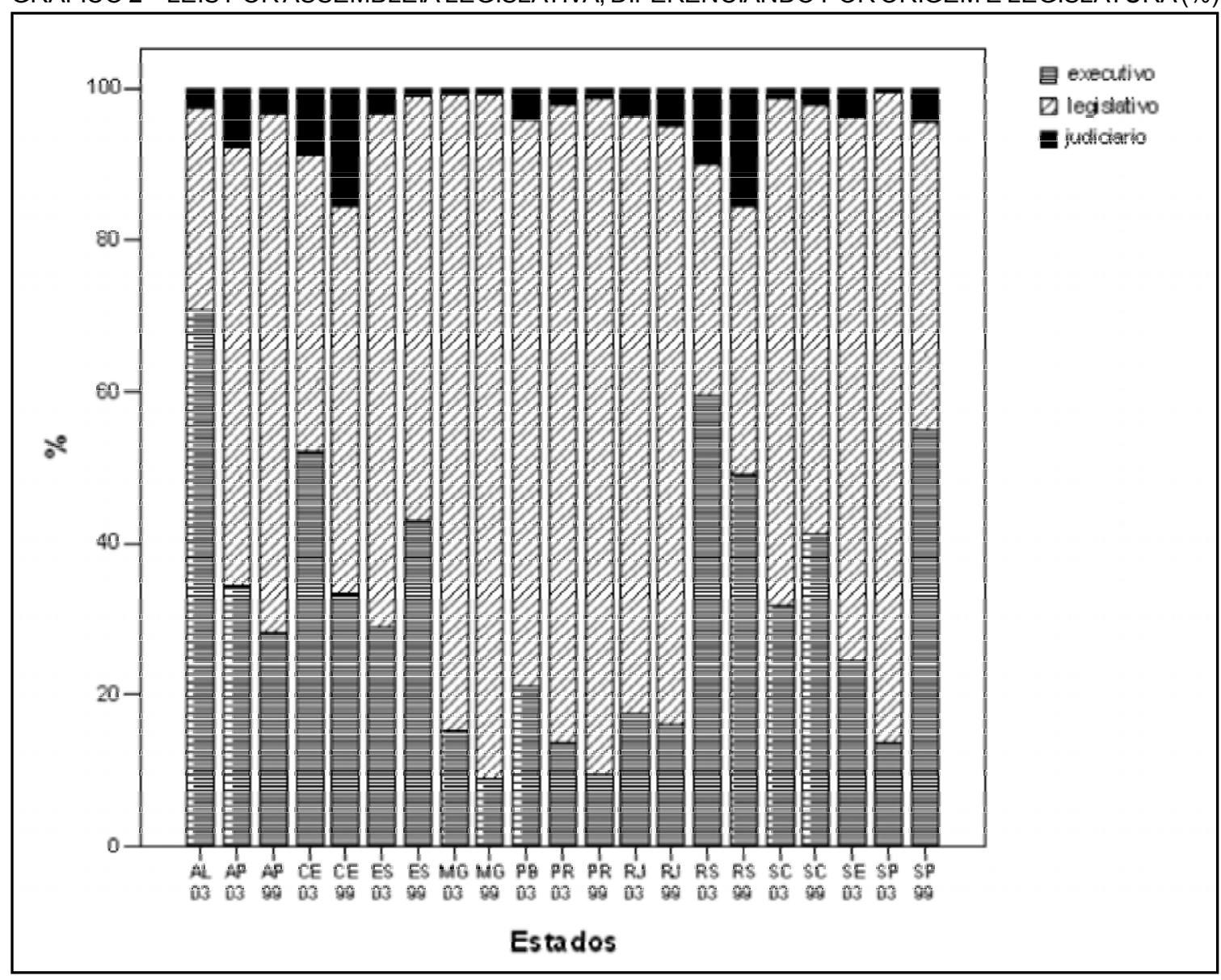

Fonte: Banco de Dados Legislativos das Assembléias Estaduais.

A primeira observação a ser feita é que os governadores e o poder Judiciário são ainda mais bem-sucedidos se comparados às propostas oriundas de deputados estaduais. Entretanto, cabe salientar que há diferenças significativas entre os estados. Em Minas Gerais, por exemplo, a taxa de sucesso dos governos é elevada, porém menor que a encontrada para os demais casos e até menor que a do poder executivo federal. Em outros estados, porém, a capacidade de aprovação de projetos legislativos iniciados pelo poder executivo é quase que total, como em Sergipe e Paraíba, ou superior a 90\%, como no Ceará, Santa Catarina, Amapá e Alagoas. Da mesma forma, quanto à taxa de sucesso das propostas dos deputados estaduais, elas são baixas no Rio de Janeiro, em São Paulo e no Rio Grande do Sul, mas elevadas em outros casos. Destaca-se o caso de Sergipe, onde quase a totalidade das propostas oriundas do poder legislativo chegam a ser aprovadas. Cabe uma reflexão sobre as diferenças entre as legislaturas. Percebe-se que para a mesma Assembléia
Legislativa as taxas de sucesso mantêm-se relativamente estáveis. Entretanto, há variações significativas não desprezíveis. $\mathrm{O}$ caso peculiar é o do Rio Grande do Sul que registra para a legislatura 1999-2002 uma taxa de sucesso do poder Executivo de 78,3\%, valor distante do observado para a legislatura sucessiva, fixada em 91,1\%. Mesmo que com menor ênfase, o mesmo pode ser dito para o Espírito Santo e o Paraná ou, olhando para as normas oriundas do poder Legislativo, para Santa Catarina.

Dos dados apresentados acima extraímos duas importantes considerações. Por um lado, o sucesso das propostas do Legislativo, algo não registrado para o âmbito nacional, dentro da Câmara dos Deputados. Por outro lado, sempre olhando para as taxas de sucesso, destaca-se a presença de variações registradas entre os estados e entre as legislaturas nos estados. Cabe, portanto, a seguinte pergunta: como a literatura explica esses dois aspectos? 


\section{DIFERENÇAS E SIMILARIDADES ENTRE OS ESTADOS: ALGUMAS INTERPRETA- ÇÕES}

Nesta seção abordaremos a questão inerente às variações encontradas entre os estados nas taxas de sucesso deixando para a seção sucessiva a tarefa de dar uma resposta conclusiva para o sucesso elevado do poder Legislativo ${ }^{6}$. De acordo com a interpretação "clássica", na medida em que foi a primeira a ser formulada nos anos 1990, haveria uma preponderância do poder Executivo estadual frente à subordinação dos respectivos legislativos. Em geral, nos estados "não há eqüipotência entre os poderes, mas sim uma hipertrofia do executivo, configurando um sistema ultrapresidencial" (ABRUCIO, 1998, p. 110-111). A essência do argumento é que os governadores controlam as assembléias legislativas que, por sua vez, exercem apenas um papel homologatório. A relação básica entre o poder Executivo e o poder Legislativo é expressa nesses termos. Os deputados estaduais, frente à fraqueza das agremiações partidárias, dependeriam do acesso a recursos públicos. Assim, eles garantiriam o apoio ao Governador que, em resposta, promoveria a distribuição de recursos ou cargos do poder Executivo.

Dentro das possíveis implicações que essa forma de argumentar acarreta, uma implicação central para este trabalho é que a dinâmica do processo legislativo estadual é dominada pelo poder Executivo. Assim, nas palavras de Fernando Abrucio, "os governadores possuíam controle total das assembléias legislativas, aprovando, com grande facilidade, os principais projetos de lei que lhes interessavam" (idem, p. 163). Essa afirmação é seguida por estudos semelhantes que verificaram a grande capacidade de aprovação de legislação iniciada pelo poder Executivo em outras assembléias estaduais brasileiras como São Paulo (ABRUCIO, CARVALHO TEIXEIRA\& COSTA, 2001), Espírito Santo (DOMINGUES, 2001) e, mesmo que de maneira menos enfática, para o

\footnotetext{
6 Doravante a análise será restrita às propostas oriundas do poder Executivo e do poder Legislativo. Nosso propósito no artigo é discutir os desempenhos desses dois atores, assim como a relação entre eles. As propostas de autoria do poder Judiciário, do Tribunal de Contas, do Ministério Público etc., remetem a um conteúdo específico, mais limitado e circunscrito, que não será explorado neste artigo.
}

Rio Grande do Sul (GROHMAN, 2001) e Paraná (BRAGA \& FRANÇA, 2008). Em síntese, essa perspectiva desenvolve-se em torno da contraposição entre, por um lado, um poder Executivo com fortes poderes e, por outro, um poder Legislativo fraco, seja porque fracamente organizado internamente, seja em razão do fato de que os deputados estaduais, frente à fraqueza das agremiações partidárias, dependem do acesso a recursos públicos que são de monopólio do Governador.

Essa forma de argumentar é válida, mas deve ser melhor definida. Se não há dúvida de que os governadores são fortes, importante é enfatizar o fato de que essa força não é derivada essencialmente da fraqueza da assembléia legislativa, mas definida pelo arranjo institucional brasileiro. No caso, trata-se de olhar para as prerrogativas constitucionais que a Carta de 1988 e as respectivas constituições estaduais conferem ao Governador (o mesmo argumento está contido em Souza (2005), Arreche (2009) e Leite e Santos (2010)). De fato, o escopo decisório do poder Legislativo estadual sofre de grande limitação na produção legislativa. A Constituição Federal define (em seu art. $25, \S 1^{\circ}$ ) que "são reservados aos Estados as competências que não lhes sejam vedadas por esta Constituição". Como o texto constitucional é extremamente detalhado nas atribuições da União, dos estados e dos municípios, compete estritamente aos governos estaduais legislar de modo "concorrente"7 com a União em assuntos: tributários, econômicos, de políticas públicas (educação, saúde, desenvolvimento, meio-ambiente etc.) e administração pública geralmente, a partir de critérios claramente expressos na Constituição e nas leis complementares federais. Além disso, a mesma constituição elevou os municípios ao status de

\footnotetext{
7 O Art. 24. da Constituição Federal de 1988 determina que "Compete à União, aos Estados e ao Distrito Federal legislar concorrentemente sobre: [...] $\S 1^{\circ}-$ No âmbito da legislação concorrente, a competência da União limitarse-á a estabelecer normas gerais. $\S 2^{\circ}-$ A competência da União para legislar sobre normas gerais não exclui a competência suplementar dos Estados. $\S 3^{\circ}-$ Inexistindo lei federal sobre normas gerais, os Estados exercerão a competência legislativa plena, para atender a suas peculiaridades. $\S 4^{\circ}-$ A superveniência de lei federal sobre normas gerais suspende a eficácia da lei estadual, no que the for contrário".
} 
entes federativos, reser-vando a esses o home rule e a plena autonomia política ${ }^{8}$. Portanto, toda esfera de "assuntos de interesse municipal" tornou-se objeto normativo de decisões legislativas autônomas dos governos municipais. Como a União possui competência normativa exclusiva abrangente (29 temas, que vão do direito civil e penal à propaganda comercial e serviço postal), resta aos estados o papel de produzir norma jurídica muito limitada9 .

Ainda mais importante é dizer que, em todos os estados, compete exclusivamente ao poder Executivo propor legislação sobre: o efetivo e funcionamento da Polícia Militar, o regime (cargos, salários e pensões) do serviço público, questões tributárias e orçamentárias, a defensoria pública e a estrutura administrativa do poder executivo (secretarias e demais órgãos). Isso pode explicar o volume elevado de propostas apresentadas e aprovadas pelos governadores. O sucesso delas está relacionado com a natureza dessas propostas, independentes de aspectos ideológicos - já que prerrogativas dos referidos atores - e vinculadas à gestão dessas políticas, visto que, geralmente, as políticas públicas são definidas em lei complementar ou na própria Constituição Estadual. Nesse sentido, para os interesses individuais dos parlamentares estaduais brasileiros - ou para os próprios partidos -, parece ser preferível um poder Executivo com suficiente capacidade de produção legislativa a um Governador fraco e incapaz de implementar suas proposições no Parlamento. Somente no primeiro caso haverá algum espaço para que a negociação implemente regulamentações com ganhos mútuos entre os atores. Inclusive, para a maioria dos parlamentares, um Governador com capacidade de implementação de uma agenda legislativa deve ser preferível a um Executivo incapaz de imple-

\footnotetext{
8 Para a compreensão da dinâmica referente à criação e às prerrogativas constitucionais dos municípios após a Constituição de 1988, ver Tomio (2002; 2005a; 2005b).

9 Não apenas a Constituição limita a capacidade autônoma do legislador estadual, mas também as interpretações do Supremo Tribunal Federal (STF) são em sua maioria favoráveis ao Governo Federal. Assim, as tentativas de introduzir novas regras nas constituições estaduais ou em leis estaduais foram declaradas inconstitucionais pelo STF (SOUZA, 2005). Para uma referência recente sobre as Ações Diretas de Inconstitucionalidade (Adins) impetradas por estados contra a União e pela União contra os estados, ver Oliveira (2009).
}

mentar qualquer legislação. Isso, de certa forma, explica as altas taxas de sucesso encontradas nas propostas oriundas do poder executivo.

Entretanto, o argumento que acabamos de esboçar não explica as variações nas taxas de sucesso das propostas do governo encontradas entre os estados. Para além do mais, se houvesse essa troca de apoio entre governo e deputados percebidos estes como atores individuais -, não deveríamos observar taxas de sucesso menores para as propostas dos próprios parlamentares. Vale também notar que, do ponto de vista formal, a atribuição de competências ao poder executivo estadual é quase idêntica nos estados, com exceção da Medida Provisória e das Leis Delegadas ${ }^{10}$. Os constituintes estaduais reproduziram, por imposição e não necessariamente por escolha, a delegação de prerrogativas legislativas da Presidência presente na Constituição Federal. Ou seja, o aspecto formal desenhado pelos constituintes não pode explicar tudo, em particular as variações aqui encontradas entre os estados. No nosso entender seria necessário passar a considerar a dinâmica político-partidária interna a cada estado. Em outros termos, a subordinação do poder Legislativo não pode ser uma explicação válida para todas as assembléias legislativas e o sucesso do governo deveria ser analisado levando em conta também a dimensão política de cada estado. Assim, a melhor forma de analisar os outcomes legislativos é focar a contraposição entre governo, a maioria parlamentar e a própria oposição, deixando de lado a mera contraposição entre os poderes Executivo e Legislativo. Ou seja, na linha da literatura recente que estuda as relações entre Executivo e Legislativo em sistemas presidencialistas, a exaltação da dimensão do presidencialismo de coalizão constitui um ponto de partida válido também para o estudo da dinâmica no âmbito subnacional. Interessante notar que, ainda em 2001, alguns autores, mesmo sem questionar a tese da força dos governadores, haviam mos-

10 Os governadores, diferentemente do Presidente da República, possuem o poder de editar Medidas Provisórias (MPs) apenas em Tocantins, Santa Catarina, Acre, Paraíba, Maranhão e Piauí. Mas vale notar que, nesses casos, há fortes limitações à edição de MPs estaduais, o que não permitem que esse mecanismo contribua significativamente para a atribuição de um maior poder ao poder Executivo no processo decisório estadual. Para mais detalhes ver o Apêndice. 
trado que o Executivo era menos bem-sucedido em alguns casos. Assim, ainda analisando a mesma legislatura (a de 1995-1998), Fátima Anastásia (2001) e Fabiano Santos (2001a), ressaltam o fato de que, no caso das assembléias legislativas de Minas Gerais e do Rio de Janeiro, não se verificou a preponderância legislativa do poder Executivo. A dimensão partidária era, porém, ainda pouco explorada pelos autores.

Em estudo mais recente sobre a Assembléia Legislativa de Minas, Felipe Nunes (2008a) mostra que, por meio do exame das votações nominais, os partidos que apóiam o governo tendem a ter um comportamento partidário - seguindo assim o padrão encontrado no Congresso Nacional -, mesmo que se observe a não cooperação quando as votações são "custosas". O mesmo autor, analisando as respostas a um questionário aplicado no Legislativo mineiro e na Assembléia Legislativa do Rio Grande do Sul, informa que "a maior parte dos parlamentares afirma que a estratégia mais eficiente para que o Governador obtenha apoio legislativo seja a negociação com os partidos" (NUNES, 2008b). Dado esse que foi confirmado em exame comparativo recente sobre 12 assembléias legislativas (NUNES, 2009). Em abordagem similar, Castro, Anastasia e Nunes (2009) têm de fato mostrado que existem diversos sistemas partidários no âmbito subnacional, sendo possível classificar a maioria dos partidos na escala direita-esquerda. E, em estudo de caso sobre a Assembléia de Santa Catarina, mostrou-se que "no conjunto dos dados analisados a dimensão governo/oposição revelou ser mais significativa na formação de coalizões em plenário do que o posicionamento dos partidos na escala ideológica" (CARREIRÃO \& PERONDI, 2009, p. 137). Ou seja, a dinâmica das decisões legislativas segue um padrão partidário e o apoio dado ao Governador não é incondicionalmente apartidário.

Em síntese, não podemos de imediato concluir que a lógica da relação Executivo-Legislativo nos estados seja, necessariamente, a de subordinação da Assembléia ao Governador. Afinal, se a maior parte do arranjo institucional brasileiro segue as mesmas diretrizes, fica difícil explicar a variação encontrada nos estados apenas pela variação institucional. É a partir desse ponto que a perspectiva que enfatiza as dinâmicas político-partidárias acrescenta um entendimento mais completo do fenômeno estudado. Nosso argumento pode ser sintetizado da seguinte forma: o arranjo institucional ajuda-nos a compreender o fato de que o Governador detém o monopólio da agenda legislativa à qual o deputado estadual está subordinado para a implementação de uma agenda pública, mas é a dinâmica partidária que nos informa quanto às diferenças encontradas entres as próprias assembléias legislativas.

Uma forma de dimensionar a dinâmica "política" da relação entre os atores seria mostrar as diferenças entre as taxas de sucesso do governo comparando entre governos majoritários e minoritários. Infelizmente não temos informações detalhadas para proceder a uma análise desse tipo. Seguimos, portanto, duas estratégias investigativas alternativas. Uma primeira forma de encontrar evidências relativas à dinâmica políticopartidária para explicar os outcomes legislativos é observar o sucesso legislativo ao longo da legislatura. Se, como sugerido por parte da literatura, o poder Executivo exerce forte controle sobre o poder Legislativo, então o sucesso registrado não deveria variar ao longo da legislatura, mas manter-se constante. Da mesma forma, as taxas de sucesso do poder Legislativo deveriam seguir o mesmo padrão. Alternativamente, pode-se argumentar que o término do mandato amplia a responsabilidade dos parlamentares para com seus eleitores. Dessa forma, aprovar projetos de iniciativa do poder Executivo que coloquem em risco a reeleição individual dos parlamentares, como medidas impopulares ou que afetem grupos de eleitores específicos, tornar-se-ia mais difícil quando se aproxima o período eleitoral. Além disso, aprovar proposições de outros parlamentares pode estar inserido na expectativa de reciprocidade e o fim do mandato pode diminuir a confiança na cooperação entre os parlamentares.

Para verificarmos se efetivamente há variação no sucesso do poder Executivo e do poder Legislativo durante a mesma legislatura comparamos o valor médio do sucesso de cada legislatura com aquele registrado no último ano de cada governo ${ }^{11}$. Os resultados são expostos nos dois gráfi-

11 A melhor forma de proceder seria comparar entre a proporção de leis apresentadas e aprovadas no mesmo ano. Entretanto, os dados que possuímos informam apenas o ano de apresentação do projeto, e não quando ele foi aprovado. A solução encontrada foi, portanto, comparar a 
cos a seguir. Antes de comentá-los, é necessária uma nota metodológica. Os dois eixos do gráfico reportam as taxas de sucesso para, respectivamente, a legislatura inteira (quatro anos) e o último ano de governo. A linha que corta o gráfico representa a reta que nos permite introduzir o problema em termos contrafactuais. No caso, se a taxa de sucesso da legislatura fosse coincidente com a encontrada no último ano de governo, o estado em questão deveria posicionar-se na linha, deslocando-se nela apenas em função do volume de normas aprovadas. A título de exemplo, supomos que exista um hipotético estado da Guanabara. Imaginamos que as taxas de sucesso sejam de $50 \%$ para as propostas do poder executivo durante a legislatura inteira e também para o último ano de governo. Conforme mostrado no Gráfico 4, Guanabara posiciona-se no eixo justamente por registrar os mesmos níveis de sucesso. Conseqüentemente, se um estado encontra-se abaixo da linha que corta o gráfico, isso significa que o sucesso de governo (ou, se for o caso, do poder legislativo) no último ano da legislatura é menor que o valor médio para o período inteiro. Vice-versa, casos acima da linha sinalizam para uma taxa de aprovação maior no último ano de governo.

GRÁFICO3-TAXAS DE SUCESSO PARAOS PROJETOS DO PODER EXECUTIVO DURANTEALEGISLATURA E NO ÚLTIMO ANO DE GOVERNO (\%)

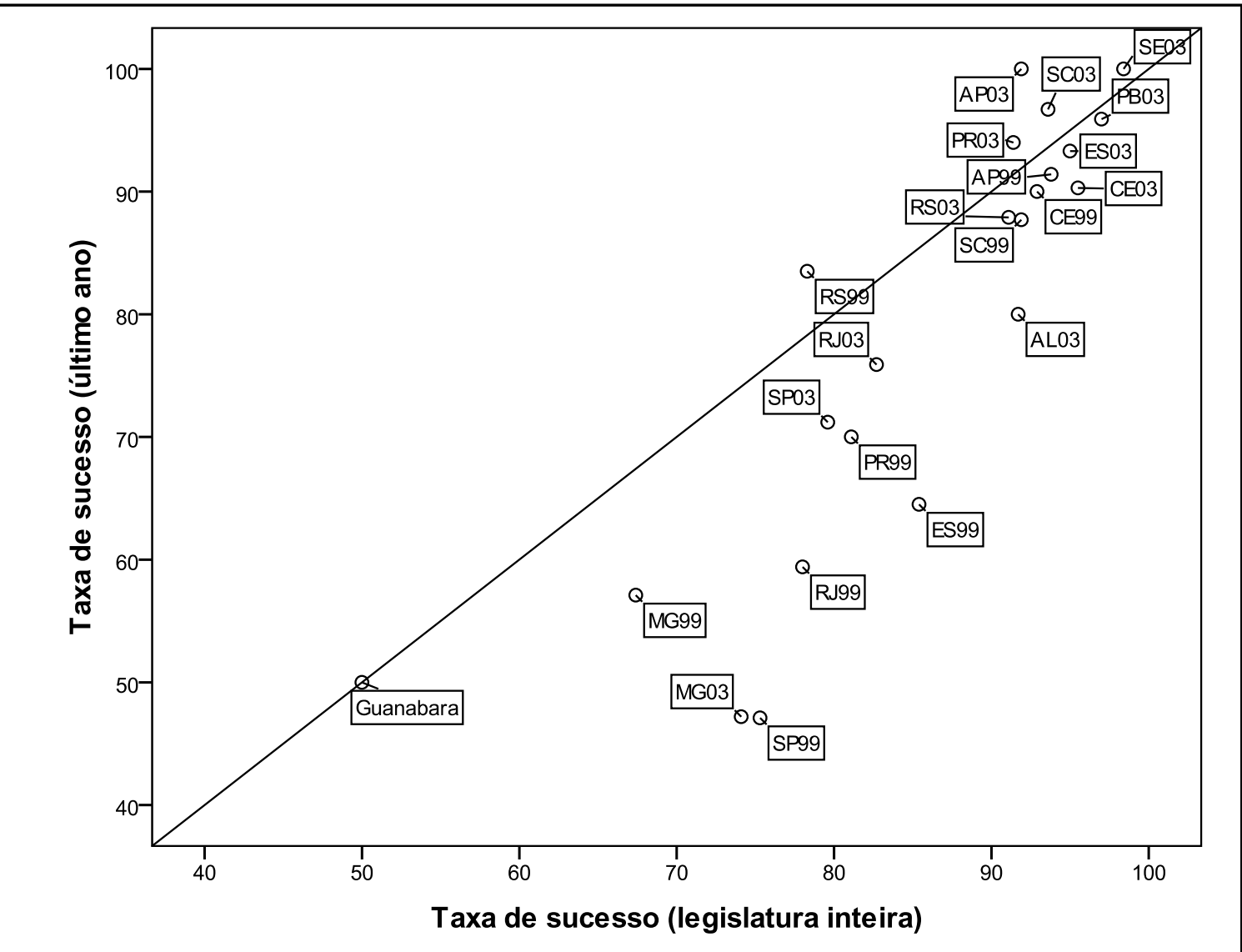

Fonte: Banco de Dados Legislativos das Assembléias Estaduais.

taxa de sucesso para a legislatura inteira e a registrada no quarto ano, último de governo. Sabemos que todos os projetos apresentados no quarto ano foram devidamente analisados naquele período, já que esse era o último ano da legislatura. Dessa forma, temos um valor mostrando quanto o sucesso para o último ano distancia-se da média encontrada para a legislatura inteira. 
GRÁFICO 4 -TAXAS DE SUCESSO PARA OS PROJETOS DO LEGISLATIVO DURANTE A LEGISLATURA E NO ÚLTIMO ANO DE GOVERNO (\%)

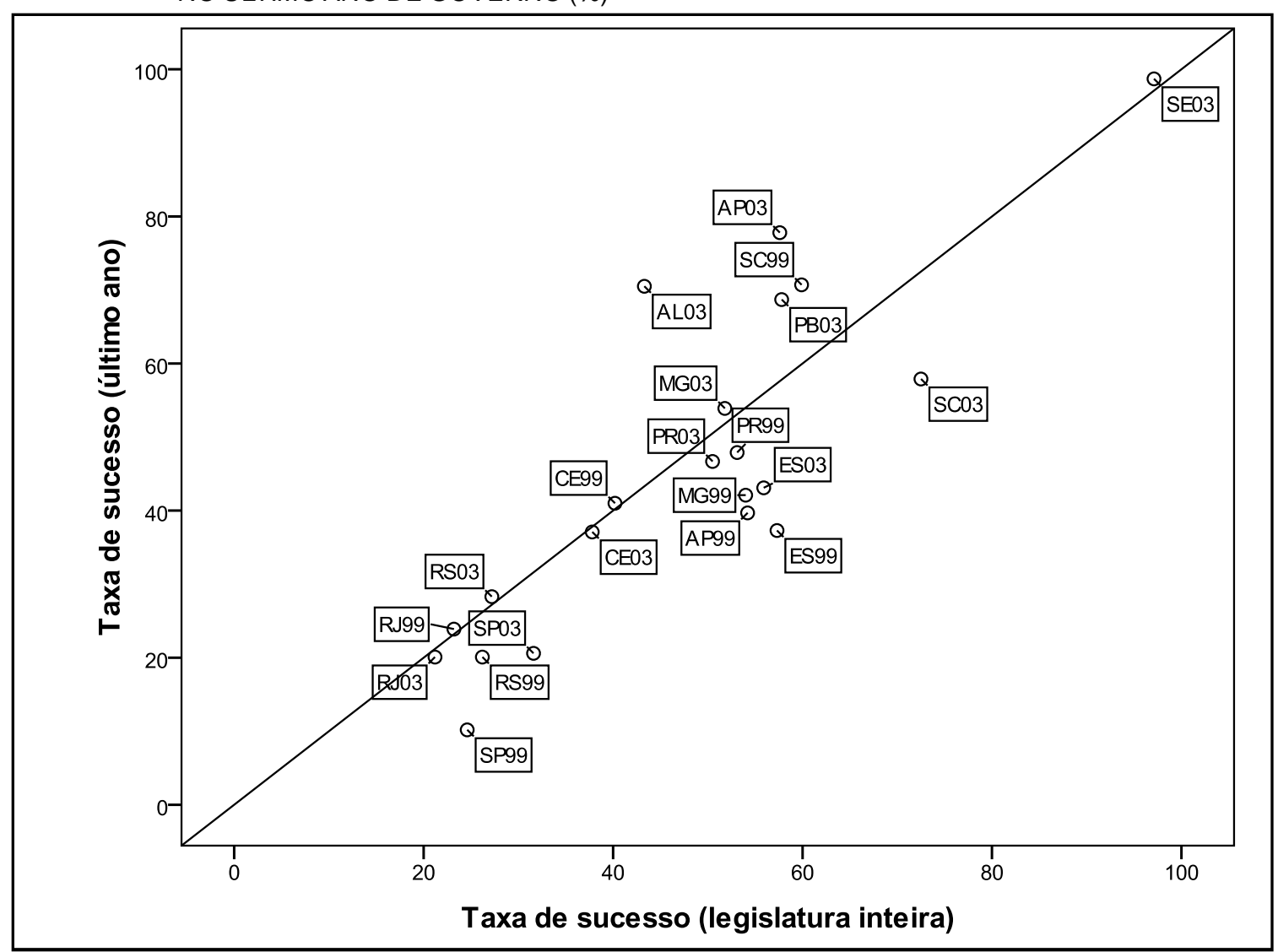

Fonte: Banco de Dados Legislativos das Assembléias Estaduais.

Podemos observar, no Gráfico 3, que o insucesso do Governador é mais do que evidente na legislatura 1999-2002 em Minas Gerais, São Paulo, Rio de Janeiro, Espírito Santos e, em menor medida, no Paraná. Na legislatura sucessiva isso ocorre em Minas Gerais e Alagoas, e menos intensamente no Paraná e São Paulo. Nos demais estados as diferenças são mínimas ou quase que nulas. Esses casos não excluem a priori uma dinâmica do processo legislativo baseada em uma contraposição entre governo e oposição. Aqui, talvez, estejamos perante uma coalizão que apóia o Governador e demonstra-se coesa e disciplinada durante a legislatura inteira. Obviamente, apenas uma análise mais aprofundada de cada caso poderia encontrar evidências nesse sentido. Quando consideramos a legislação introduzida pelos deputados estaduais (Gráfico 4), nota-se que apenas São Paulo e Espírito Santo confirmam a tendência a um valor mais elevado de propostas não aprovadas. Ou seja, parece que nesses dois estados a instabilidade da coalizão refletiu-se não apenas no sucesso do poder executivo, mas também no do poder legislativo. Não é o caso, porém, de Minas Gerais e de Alagoas. Aliás, este último caso é interessante, mostrando que, se por um lado o poder executivo não é bem sucedido no último ano de governo, os deputados estaduais têm uma taxa de sucesso mais elevada daquela encontrada durante a legislatura inteira. Esses dados, em geral, não são conclusivos. Entretanto, sinalizam para uma possível dinâmica interna às próprias coalizões para explicar o sucesso decrescente (ou constante) do poder executivo e do próprio poder legislativo ${ }^{12}$.

12 Em estudo conduzido para Minas Gerais sobre três legislaturas seguidas (1995-2005), Nunes (2008a) mostrou que as taxas de sucesso dos governadores foram menores no governo Azeredo, em particular em seus últimos dois anos. Entretanto, isso não aconteceu em outros governos, como o de Itamar Franco. De acordo com Tomio (2006), há uma nítida associação em Santa Catarina entre o declínio na taxa de aprovação de proposições do poder Executivo estadual catarinense e o decurso da legislatura parlamentar. Fato que, porém, não é constatado para o poder Legislativo. 
Uma forma alternativa em busca de evidências para a presença de uma dinâmica procedimental de cunho partidário é considerar os casos de conflito manifesto entre Executivo e Legislativo.
Isso foi possível por meio do estudo do volume e do resultado dos vetos totais e parciais. Os dados apresentados nas duas tabelas a seguir oferecem evidências em tal sentido.

TABELA 3 - MENSAGEM DE VETO ENVIADAS PELO GOVERNADOR ÀS ASSEMBLÉIAS LEGISLATIVAS

\begin{tabular}{|l|c|c|c|c|c|c|}
\hline \multirow{2}{*}{ ESTÃDOS } & \multicolumn{2}{|c|}{ PROJETOS DO EXECUTVO } & \multicolumn{3}{c|}{ PROJETOS DO LEGISLATIVO } \\
\cline { 2 - 7 } & $\begin{array}{c}\text { VETOS } \\
\text { TOTAIS }\end{array}$ & $\begin{array}{c}\text { VETOS } \\
\text { PARCIAIS }\end{array}$ & TOTAL & $\begin{array}{c}\text { VETOS } \\
\text { TOTAIS }\end{array}$ & $\begin{array}{c}\text { VETOS } \\
\text { PARCIAIS }\end{array}$ & TOTAL \\
\hline Alagoas & 1 & 9 & 10 & 29 & 1 & 30 \\
Amapá & 2 & 0 & 2 & 44 & 0 & 44 \\
Ceará & 0 & 16 & 16 & 22 & 7 & 29 \\
Espírito Santo & 22 & 42 & 64 & 524 & 49 & 573 \\
Minas Gerais & 3 & 45 & 48 & 85 & 49 & 134 \\
Paraíba & 3 & 5 & 8 & 47 & 5 & 52 \\
Paraná & 6 & 28 & 34 & 483 & 16 & 499 \\
Rio de Janeiro & 6 & 69 & 75 & 594 & 130 & 724 \\
Rio Grande do Sul & 5 & 58 & 63 & 146 & 10 & 156 \\
Santa Catarina & 7 & 40 & 47 & 373 & 35 & 408 \\
São Paulo & 0 & 39 & 39 & 328 & 54 & 382 \\
Sergipe & 0 & 0 & 0 & 5 & 0 & 5 \\
TOTAL & 53 & 350 & 403 & 2675 & 356 & 3031 \\
\% & 13,2 & 86,8 & 100 & 88,3 & 11,7 & 100 \\
\hline
\end{tabular}

Fonte: Banco de Dados Legislativos das Assembléias Estaduais.

TABELA 4 - RESULTADO DAS MENSAGENS DE VETO

\begin{tabular}{|l|c|c|c|c|c|c|}
\hline \multirow{2}{*}{ ESTADOS } & \multicolumn{2}{c|}{ PROJETOS DO EXECUTIVO } & \multicolumn{3}{c|}{ PROJETOS DO LEGISLATIVO } \\
\cline { 2 - 7 } & $\begin{array}{c}\text { VETOS } \\
\text { MANTIDOS }\end{array}$ & $\begin{array}{c}\text { VETOS } \\
\text { DERRUBADOS }\end{array}$ & TOTAL & $\begin{array}{c}\text { VETOS } \\
\text { MANTIDOS }\end{array}$ & $\begin{array}{c}\text { VETOS } \\
\text { DERRUBADOS }\end{array}$ & TOTAL \\
\hline Alagoas & 2 & 0 & 2 & 29 & 0 & 29 \\
Amapá & 1 & 1 & 2 & 42 & 2 & 44 \\
Ceará & 9 & 0 & 9 & 27 & 2 & 29 \\
Espírito Santo & 34 & 28 & 62 & 320 & 252 & 572 \\
Minas Gerais & 42 & 6 & 48 & 92 & 42 & 134 \\
Paraíba & 7 & 0 & 7 & 41 & 11 & 52 \\
Paraná & 18 & 13 & 31 & 430 & 64 & 494 \\
Rio de Janeiro & 33 & 42 & 75 & 498 & 226 & 724 \\
Rio Grande đó & 31 & 32 & 63 & 81 & 75 & 156 \\
Sul & & & & & 117 & 408 \\
Santa Catarina & 42 & 4 & 46 & 291 & 157 & 362 \\
Săo Paulo & 16 & 5 & 21 & 205 & 0 & 5 \\
Sergipe & 0 & 0 & 0 & 5 & 948 & $3009^{2}$ \\
TOTAL & 235 & 131 & 366 & 2061 & 31,5 & 100 \\
\% & 64,2 & 35,8 & 100 & 68,5 & & 45 \\
\hline
\end{tabular}

FONTE: Banco de Dados Legislativos das Assembléias Estaduais.

1. Os casos sem informação são: oito para Alagoas; sete para Ceará; dois para Espírito Santo; um para Paraíba; um para Santa Catarina e 18 para São Paulo.

2. Os casos sem informação são: um para Alagoas e Espírito Santo e 20 para São Paulo. 
A Tabela 3 informa-nos sobre os vetos apresentados, distinguindo entre os tipos de vetos. O poder Executivo vetou, no total, 403 das suas propostas e 3031 daquelas dos parlamentares ${ }^{13}$. Há de notar-se, porém, uma variação no tipo de comportamento adotado pelo Governador quando decide vetar. O veto parcial tende a ser mais utilizado no caso de propostas oriundas do próprio poder Executivo, enquanto os vetos totais afetam diretamente as propostas dos deputados. A única exceção parece ser Espírito Santo e Sergipe. No primeiro caso, há um volume elevado de vetos totais em torno de propostas do próprio poder executivo. No caso de Sergipe, a prática do veto não parece ser costumeira indicando, de certa forma, que aqui as decisões ocorrem sob a égide do consenso. Interessante constatar, também, que alguns estados vetam mais, como Rio de Janeiro, Espírito Santo ou Paraná ${ }^{14}$.

No que tange às duas modalidades de uso do veto, Shugart e Carey (1992) tem salientado recentemente que o veto parcial aumenta significativamente os poderes do poder Executivo. Por esse mecanismo institucional, o Presidente (ou o Governador, no caso de estudo) não é obrigado a aceitar legislações inteiras aprovadas pelo poder Legislativo. Ter a capacidade de bloquear partes da lei obriga os parlamentares a reverem suas posições e barganhar com o poder Executivo. $\mathrm{O}$ veto total, por outro lado, significa uma recusa explícita do poder Executivo em aceitar o "pacote" aprovado pelo poder Legislativo. Nesse caso, só resta aos parlamentares manterem sua posição ou acatar a decisão do Executivo. O veto parcial, portanto, revela-se um mecanismo institucional muito mais poderoso para o Executivo. Ao aplicálo, o Executivo dificulta a formação de maiorias contrárias no Parlamento, dado que os legisladores não têm que optar entre nenhuma lei e a lei aprovada pelos parlamentares. Os membros da maioria

13 Diferentemente da análise anterior preferimos mostrar os dados por estado sem diferenciar por legislatura de modo a tornar a exposição mais inteligível. Eventuais diferenças entre as legislaturas serão apontadas ao longo do texto.

14 Importante dizer que em alguns casos os vetos são concentrados em uma legislatura. No Espírito Santo, Santa Catarina e Rio Grande do Sul, mais de dois terços dos vetos são apresentados na legislatura 1999-2003. Isso reforça o argumento de que há variações internas aos estados entre uma legislatura e outra que, evidentemente, remetem ao formato do jogo político aí presente. parlamentar que aprovaram a legislação podem ter preferências distintas quanto aos detalhes da legislação; ou, em um caso mais favorável para o Executivo, leis aprovadas por maiorias simples não conseguem agregar uma maioria absoluta para derrubar o veto parcial do Executivo. Dessa forma, é muito mais difícil para os legisladores, devido aos dilemas da ação coletiva, derrubar um veto parcial do que um veto total do Executivo. Isso explica o fato de que o Executivo adote mais o veto parcial para suas próprias propostas.

A Tabela 4 reporta os dados sobre os resultados dos vetos. O que importa, aqui, é saber se o Governador foi bem-sucedido e é por essa razão que a distinção entre vetos totais e parciais não foi mantida. Os dados evidenciam que, quando se trata de propostas do poder Executivo, na maioria dos casos os vetos (como visto na tabela anterior em sua maioria parciais) não são derrubados. Há uma parcela significativa de vetos derrubados $(35,8 \%)$, que se restringem aos casos de Rio de Janeiro, Rio Grande do Sul, Espírito Santo e, em menor medida, Paraná. Interessante também o dado de 948 vetos derrubados para as propostas oriundas dos deputados (31,5\% do total), em particular para Espírito Santo, Rio de Janeiro, Santa Catarina, Rio Grande do Sul e São Paulo. Ou seja, os governos têm aproximadamente um terço de seus vetos totais rejeitados; certamente um número pouco desprezível dentro de uma perspectiva que percebia o Governador como ator onipotente. Novamente, é claro que para esses casos a explicação dos outcomes legislativos deve passar pela compreensão da interação entre as forças políticas, dentro de uma lógica de contraposição entre governo, base aliada e oposição.

Certamente, é verdade que muitas das considerações até aqui desenvolvidas deveriam ser ponderadas em função da natureza da política em discussão. Nunes, por exemplo, sugere que no caso de Minas Gerais "os partidos da base aliada formal costurada pelo Governador tendem a não cooperar efetivamente com o chefe do Executivo nas votações custosas" (NUNES, 2008a, p. 121). No que tange à produção legislativa dos deputados estaduais, talvez, o sucesso poderia ser explicado em função da baixa qualidade das normas apresentadas e votadas. Assim, claramente, tornase necessária uma reflexão mais aprofundada em torno da qualidade das normas produzidas. A seção a seguir aborda esse ponto. 
IV. O CONTEÚDO DA PRODUÇÃO LEGISLATIVA E O PAPEL DAS ASSEMBLÉIAS ESTADUAIS

O que esperar da qualidade das propostas apresentadas e sancionadas pelas assembléias legislativas estaduais? A literatura que discute esse aspecto para o Congresso Nacional explica o conteúdo das leis partindo da análise dos incentivos vindos do próprio sistema eleitoral. Como observado por vários autores, a estrutura dos incentivos eleitorais presentes para o caso brasileiro tornaria raros os projetos de lei de iniciativa do Congresso que tratam de questões fundamentais (MAINWARING, 1999; AMES, 2001). Em particular, o predomínio das cam-panhas eleitorais personalizadas dos parlamentares (AMES, 1995a; 1995b), a incapacidade dos líderes de partido de selecionar os candidatos (MAINWARING, 1999; AMES, 2001) assim como a descentralização do sistema político juntamente ao fator federal (AMES, 1995a; SAMUELS, 2000) e a competição intrapartidária, incentivam o comportamento personalista dos legisladores. Além do mais a literatura enfatiza o fato de que os políticos brasileiros tendem a ter uma distribuição dos votos concentrada em algumas regiões ou cidades (AMES, 2001; para uma sofisticação do problema, ver Carvalho (2003)). Isso implica que todo entendimento que diz respeito à legislação é obstinadamente caracterizado pela prática da ressalva de que as normas produzidas pelo poder Legislativo são secundárias e de relativa importância já que repletas de concessões e vantagens particularistas que concretamente podem chegar a beneficiar apenas um determinado município. $\mathrm{O}$ argumento é basicamente desenvolvido para os deputados federais, mas pode ser estendido certamente ao caso aqui estudado dos deputados estaduais. Portanto, seguindo tal argumentação, a expectativa é a de que a qualidade das normas introduzidas pelos deputados estaduais tornar-se-ia preponderantemente de cunho paroquialista $^{15}$. Por outro lado, quando se olha para o poder Executivo, a idéia é que os partidos the

\footnotetext{
15 Identificamos apenas um estudo publicado em revista cientifica que busca evidências para tese de que o conteúdo da produção legislativa dos deputados estaduais deriva do formato da distribuição dos votos. Trata-se do trabalho de Cervi (2009) sobre o Paraná, em que o autor mostrou que os deputados com votação concentrada tendem a apresentar mais propostas de caráter municipal ou regional.
}

delegam suas decisões e necessidades de investir em políticas públicas mais gerais. Isso porque o Presidente é eleito dentro de uma competição que ocorre no âmbito nacional, em que o papel dos partidos adquire dimensão central ${ }^{16}$. A característica de sua produção legislativa adquire, portanto, elementos diferentes dos que caracterizam as propostas dos parlamentares.

Para verificarmos se a prática legislativa nos estados remete a esse formato, é necessário em primeiro lugar classificar o conteúdo das normas apresentadas e votadas nas assembléias estaduais. De imediato, portanto, surge a seguinte pergunta: qual critério deve ser adotado para classificar uma norma como de tipo territorialmente limitada? Para isso decidimos apelar ao grau de abrangência da norma sobre o território estadual; critério usado em outros estudos que avaliam o conteúdo das normas no âmbito naciona $1^{17}$. De acordo com esse critério é possível identificar três tipos de propostas normativas. O primeiro tipo é o que denominamos de norma estadual. Essas são normas que afetam a população do estado como um todo ou, como no caso de benefícios para grupos específicos, parte dela. O que importa, aqui, é seu grau de abrangência territorial que afeta o estado como um todo. O segundo tipo é a norma municipal, identificada como aquela em que existe um benefício efetivo para uma determinada cidade ou, de maneira mais abrangente, um conjunto de cidades em uma determinada região do estado ${ }^{18}$. Destacamos, aqui, o termo efetivo porque há inúmeras iniciativas legislativas que mesmo reconhecidamente locais não trazem consigo

16 Para mais detalhes sobre a conexão eleitoral e uma investigação em torno da visão que os próprios deputados federais têm sobre a atuação deles na arena eleitoral e na parlamentar ver, por último, Lemos e Ricci (2011).

17 A identificação do conteúdo das leis foi feita a partir da leitura da ementa do projeto de lei. A estratégia é a mesma adotada em outros estudos que qualificam a produção legislativa do Congresso Nacional levando em conta o grau de abrangência territorial da lei. Vê-se, em particular, Amorim Neto e Santos (2003) e Ricci (2003). Para uma discussão teórica sobre os problemas da classificação do conteúdo das leis ver Ricci $(2002 ; 2010)$.

18 Apesar de termos encontrado projetos que beneficiam mais de uma cidade - como no caso de instituição de parques nacionais ou de estadualização de rodovias - preferimos adotar a denominação de norma "municipal", já que a maioria desses projetos tem sua abrangência territorial limitada ao município. 
benefícios tangíveis ou reais. São exemplos desse tipo as normas que denominam estruturas públicas ou privadas (escolas, pontes, aeroportos, ruas, praças etc.). Trata-se de propostas que têm um mero impacto simbólico sobre a comunidade local. Apesar de ser correto afirmar que a política e as relações entre os atores fortalecem-se em virtude, também, dos vínculos simbólicos locais, sabemos que o verdadeiro desafio aqui é encontrar evidências para a suposta tese da conexão eleitoral. Nesse sentido, acreditamos que apenas os benefícios reais, isto é, os tangíveis, e não os simbólicos, podem dar saliência explicativa a essa tese. Afinal, como se explicaria uma lógica do voto baseada na troca de benefícios por votos que se fundamenta na mera atribuição de políticas simbólicas, isto é, que não levam a nenhum incremento do bem-estar do eleitor? Por essa razão, portanto, decidimos criar uma categoria a parte, a terceira, para as propostas de tipo simbólico. A tabela seguinte descreve, para cada assembléia legislativa, a distribuição percentual para os três tipos de normas encontradas para as propostas oriundas do governo e do poder legislativo.

TABELA 5 - CONTEÚDO DOS PROJETOS DE LEI APRESENTADOS POR ORIGEM (\%)

\begin{tabular}{|c|c|c|c|c|c|c|c|c|}
\hline \multirow[b]{2}{*}{ ESTADOS } & \multicolumn{4}{|c|}{ EXECUTIVO } & \multicolumn{4}{|c|}{ LEGISLATIVO } \\
\hline & $\begin{array}{l}\text { ESTA- } \\
\text { DUAL }\end{array}$ & $\begin{array}{l}\text { MUNNi- } \\
\text { CIPAL }\end{array}$ & $\begin{array}{l}\text { SIMBÓ- } \\
\text { LICO }\end{array}$ & $\begin{array}{c}\text { TOTAL } \\
\text { (N) }\end{array}$ & $\begin{array}{l}\text { ESTA- } \\
\text { DUAL }\end{array}$ & $\begin{array}{l}\text { MUNNI- } \\
\text { CIPAL }\end{array}$ & $\begin{array}{l}\text { SiMBó- } \\
\text { LICO }\end{array}$ & $\begin{array}{c}\text { TOTAL } \\
(\mathrm{N})\end{array}$ \\
\hline Alagoas & 93,5 & 4,1 & 2,4 & 339 & 49,5 & 36,4 & 14,1 & 269 \\
\hline Amapá & 91,5 & 8,0 & 0,5 & 199 & 71,9 & 21,5 & 6,6 & 711 \\
\hline Ceará & 91,1 & 6,8 & 2,1 & 520 & 61,2 & 15,8 & 23,0 & 1322 \\
\hline $\begin{array}{l}\text { Espirito } \\
\text { Santo }\end{array}$ & 89,9 & 8,9 & 1,2 & 1219 & 55,1 & 17,0 & 27,9 & 3121 \\
\hline $\begin{array}{l}\text { Minas } \\
\text { Gerais }\end{array}$ & 51,0 & 29,9 & 19,1 & 628 & 37,7 & 56,4 & 5,8 & 5834 \\
\hline Paraiba & 76,4 & 17,8 & 5,8 & 174 & 45,4 & 19,8 & 34,8 & 1166 \\
\hline Paraná & 69,8 & 29,4 & 0,8 & 371 & 37,2 & 54,5 & 8,3 & 4767 \\
\hline $\begin{array}{l}\text { Rio de } \\
\text { Janeiro }\end{array}$ & 91,9 & 6,5 & 1,6 & 321 & 83,9 & 11,6 & 4,5 & 6566 \\
\hline $\begin{array}{l}\text { Rio } \\
\text { Grande } \\
\text { do Sul }\end{array}$ & 62,4 & 37,3 & 0,3 & 919 & 79,8 & 10,1 & 10,1 & 1768 \\
\hline $\begin{array}{l}\text { Santa } \\
\text { Catarina }\end{array}$ & 47,4 & 51,6 & 1,0 & 1125 & 37,0 & 47,7 & 15,3 & 2744 \\
\hline $\begin{array}{l}\text { Sáo } \\
\text { Paulo }\end{array}$ & 60,5 & 38,1 & 1,4 & 486 & 54,7 & 22,5 & 22,8 & 7327 \\
\hline Sergipe & 83,2 & 6,7 & 10,1 & 374 & 16,7 & 82,4 & 0,9 & 1251 \\
\hline TOTAL & 71,7 & 24,8 & 3,5 & 6675 & 53,8 & 32,7 & 13,5 & 36846 \\
\hline
\end{tabular}

FONTE: Banco de Dados Legislativos das Assembléias Estaduais. Para o período de 1988 a 2007, ver Figueiredo e Limongi (2007). NOTAS:

1. O dado é uma estimativa feita a partir das informações fornecidas pelo portal da Câmara de Deputados.

2. A taxa de sucesso do poder Legislativo para o período 1947-1964 é calculada a partir de Braga (2008, p. 161, Tabela 3).

Salta aos olhos, para as propostas do poder Executivo, com a exceção de Santa Catarina e Minas Gerais, o predomínio de projetos de caráter estadual ou que, de certa forma, favorecem grupos espalhados sobre o território estadual. Novamente, é importante observar as variações entre os estados, mostrando executivos mais propensos à adoção de medidas municipais como São Paulo, Rio Grande do Sul, Paraná, Santa Catarina e Minas Gerais. Quando passamos a investigar os projetos dos deputados estaduais, observamos um fenômeno aparentemente surpreendente à luz das considerações acima expostas em torno da atuação dos políticos na arena legislativa. Trata-se do baixo nível de propostas de cunho municipal apresentadas por eles em muitos estados, contradizendo, assim, a idéia de que o deputado estadual está mais interessado em envolver-se em atividades locais. $\mathrm{Na}$ maioria deles as propostas de cunho estadual são preponderantes enquanto o conteúdo municipal é mais acentuado em Sergipe, Minas Gerais, Paraná e Santa Catarina. 
Há, portanto, uma variação estadual considerável na atuação legislativa entre os parlamentares estaduais ${ }^{19}$. Entretanto, como explicar o alto volume de propostas de cunho estadual apresentadas pelos deputados estaduais? Uma resposta é que os deputados buscam sinalizar para eventuais eleitores que não necessariamente são geograficamente concentrados. É fato que muitas dessas propostas buscam beneficiar setores organizados da sociedade como policiais, militares, professores, agricultores ou categorias mais restritas ainda como taxistas, bombeiros, apicultores e assim por diante. Isso significa que, na prática, não se pode reduzir a atividade política a meras atitudes paroquiais, altamente concentradas. Os deputados têm inúmeros instrumentos para perseguir a reeleição e o da produção legislativa ordinária de cunho municipal não é talvez o mais relevante. Algo que quem foca o fenômeno da conexão eleitoral deveria levar em conta mais seriamente ${ }^{20}$.
Na Tabela 6, a seguir, apresentamos os dados relativos às taxas de sucesso por tipos de conteúdo das propostas. Como era de esperar-se o poder Executivo é bem-sucedido, independentemente do conteúdo aprovado. Em média, 88,3\% das normas estaduais, $87,3 \%$ das municipais e $88,3 \%$ das simbólicas são aprovadas. O único caso que destoa é o de Minas Gerais, em que se observa, quando comparado aos demais estados, uma taxa de sucesso relativamente baixa para os projetos a conteúdo estadual e, sobretudo, para as propostas de cunho municipal. Para as propostas oriundas do poder Legislativo, notamos o baixo índice de sucesso para as normas estaduais e o elevado valor para as propostas de cunho municipal, com a exceção do Rio de Janeiro e São Paulo. Previsivelmente, as propostas municipais dos deputados são as que têm mais chance de ser aprovadas.

TABELA 6 - TAXA DE SUCESSO DOS PROJETOS DE LEI POR ORIGEM E CONTEÚDO (\%)

\begin{tabular}{|l|c|c|c|c|c|c|}
\hline \multirow{2}{*}{ ESTADOS } & \multicolumn{3}{c}{ EXECUTIVO } & \multicolumn{3}{c|}{ LEGISLATIVO } \\
\cline { 2 - 7 } & ESTADUAL & MUNICIPAL & SIMBÓLICO & ESTADUAL & MUNICIPAL & SIMBÓLICO \\
\hline Alagoas & 92,1 & 85,7 & 87,5 & 9,8 & 80,6 & 65,8 \\
Amapá & 92,3 & 93,8 & 100 & 47,3 & 76,5 & 78,7 \\
Ceará & 94,7 & 97,1 & 100 & 19,4 & 73,3 & 66,1 \\
Espírito Santo & 87,9 & 93,6 & 92,9 & 33,3 & 71,5 & 91,7 \\
Minas Gerais & 78,4 & 54,3 & 83,3 & 19,6 & 75,8 & 44,9 \\
Paraíba & 96,2 & 100,0 & 88,9 & 23,6 & 79,7 & 88,9 \\
Paraná & 85,3 & 90,8 & 100,0 & 23,0 & 71,8 & 59,5 \\
Rio de Janeiro & 81,0 & 90,5 & 80,0 & 16,7 & 45,5 & 60,6 \\
Rio Grande do & 83,2 & 91,8 & 100 & 16,4 & 67,4 & 67,6 \\
Sul & & & & & & \\
Santa Catarina & 90,8 & 95,5 & 81,8 & 29,0 & 88,2 & 85,9 \\
Săo Paulo & 82,3 & 69,7 & 71,4 & 9,6 & 36,9 & 59,3 \\
Sergipe & 99,1 & 98,2 & 100,0 & 83,7 & 99,3 & 81,8 \\
TOTAL & 88,3 & 87,3 & 88,3 & 19,9 & 71,1 & 69,9 \\
\hline
\end{tabular}

FONTE: Banco de Dados Legislativos das Assembléias Estaduais. Para o período de 1988 a 2007, ver Figueiredo e Limongi (2007).

NOTAS:

1. O dado é uma estimativa feita a partir das informações fornecidas pelo portal da Câmara de Deputados.

2. A taxa de sucesso do poder Legislativo para o período 1947-1964 é calculada a partir de Braga (2008, p. 161, Tabela 3).

19 A variação entre os deputados estaduais no que tange ao nível de comportamento particularista foi salientado também em estudo recente de Castro, Anastasia e Nunes (2009).

20 Poderia ser sugerida uma hipótese alternativa à que apresentamos: que o ativismo legislativo dos deputados possa variar em função da magnitude do estado. No caso, em estados pequenos as duas estratégias eleitorais - produzir normas estaduais ou municipais -, poderiam confundir-se, já que aqui se elegem poucos deputados e o número de eleitores é menor. Os dados da Tabela 5, claramente, não oferecem evidências em tal sentido. Por exemplo, Minas Gerais e Paraná têm valores de normas municipais 
Em última análise, há que se fazer uma observação importante em torno das leis oriundas dos deputados. Como visto na Tabela 5, os representantes estaduais apresentam um número significativo de normas estaduais. Isso significa que, apesar de o sucesso ser menor por esse tipo de norma, seu peso relativo no conjunto da produção legislativa final pode ser bem expressivo. O gráfico a seguir mostra a distribuição percentual das propostas dos deputados que se transformaram em norma jurídica diferenciando por conteúdo. Os dados são claros. Comparado à Câmara dos Deputados, o legislador estadual reserva mais espaço para normas de cunho municipal ${ }^{21}$. Entretanto, os dados mostram que há espaço para os deputados legislar em matérias não restritas às categorias de norma municipal ou simbólica. Isso é evidente no caso do Rio de Janeiro, Amapá e Rio Grande do Sul, mas também para Ceará e Espírito Santo, em que quase um terço das leis aí produzidas pelos deputados têm características gerais já que afetam o território do estado como um todo. Se, como descrito na seção anterior, a liberdade de ação dos deputados estaduais é bastante limitada, dado que a maioria das prerrogativas de proposição relevantes é exclusiva do poder Executivo, como para leis que tratam de aspectos da administração pública ou de questões orçamentárias, é evidente que se trata fundamentalmente de normas que criam, alteram ou regulamentam "políticas públicas"22.

GRÁFICO 5 - LEGISLAÇÃO DE ORIGEM PARLAMENTAR POR CONTEÚDO (\%)

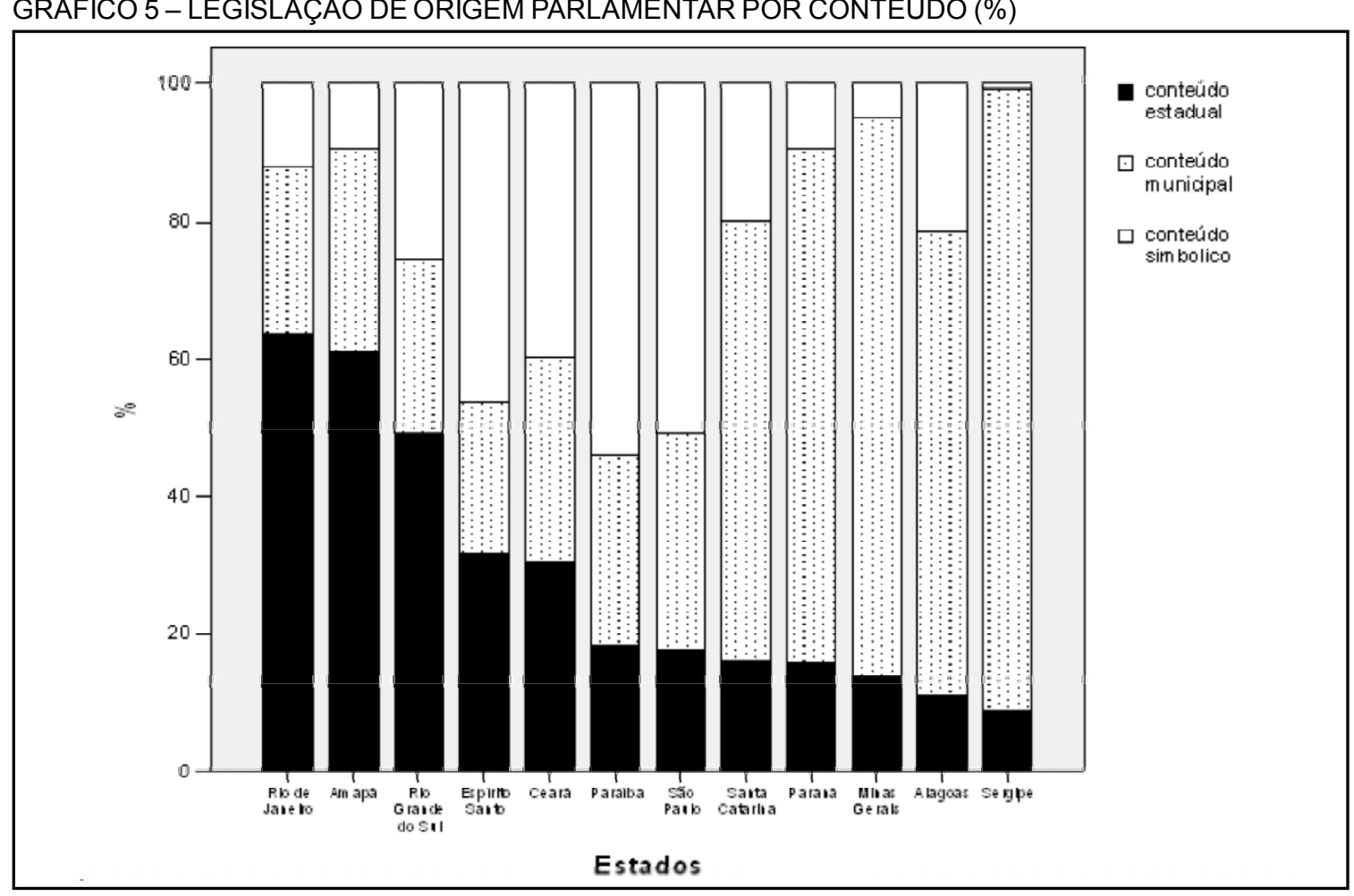

Fonte: Banco de Dados Legislativos das Assembléias Estaduais.

elevados e um número de deputados estaduais expressivo. Entretanto, outros estados com magnitude elevada como Rio de Janeiro e São Paulo apresentam índices inferiores, bem parecidos com estados cuja magnitude é baixa (como Ceará e Espírito Santo). Assim, a nosso entender, a questão do formato da produção legislativa não deriva do tamanho do distrito, mas deveria estar associada à distribuição dos votos de cada deputado. Evidências em tal sentido foram apresentadas apenas para o caso do Paraná (CERVI, 2009), necessitando-se de outros estudos que considerassem a relação entre padrões de dispersão-concentração do voto e projetos de lei em cada estado.
21 De acordo com pesquisas recentes que mensuraram a abrangência do conteúdo das leis federais, estas são majoritariamente de caráter geral. Ver a respeito os estudos de Lemos (2001), Amorim Neto e Santos (2003) e Ricci (2003). Para uma indagação sobre a democracia de 1946, em que a distribuição de benefícios locais era mais consistente, ver Santos (1995).

22 Devemos lembrar, também, que é vedado aos parlamentares estaduais aumentar as despesas previstas nos projetos de iniciativa exclusiva dos governadores. Para mais detalhes sobre os poderes formais das instituições estaduais, ver Pereira (2001) e Tomio (2006). 
Por último, uma reflexão conclusiva no que tange à produção de cunho municipal dos próprios deputados. O que prevalece é o "mercado" do reconhecimento de utilidade pública a associações e entidades sem fins lucrativos. De todas as leis aprovadas, para os 12 estados, $86,8 \%$ das normas são desse tipo ${ }^{23}$. Esse é o padrão encontrado na maioria dos estados. O percentual de normas que declaram utilidade pública é relativamente menor apenas para Paraíba, Amapá e Espírito Santo. Aqui esse tipo de norma responde por, respectivamente, $69,5 \%, 65,5 \%$ e $61,0 \%$ do total de leis paroquialistas. Nesses três estados há um número significativo de projetos que prevêem a doação de terrenos e/ou imóveis para associações, grupos, movimentos ou municípios ou, também, há leis que beneficiam diretamente o município ao conferirlhe o status de cidade turística, climática ou instituindo uma festa. O Rio Grande do Sul diferencia-se dos demais já que as leis de utilidade pública são apenas $2 \%$ do total, prevalecendo aquelas normas que transformam municípios em instâncias turísticas, climáticas ou similares.

\section{CONCLUSÕES}

A literatura convencional tem pintado um quadro das assembléias estaduais que, de certa forma, é identificável apenas para o estado de Sergipe na legislatura investigada (2003-2006). Aqui, a quase totalidade das propostas do poder Executivo e do poder Legislativo foi aprovada, sem variação na taxa de sucesso no último ano de governo, sendo os vetos uma exceção. O Governador tende a apresentar propostas gerais, enquanto os legisladores fixam-se em projetos de cunho municipal, especificadamente de utilidade pública. A Assembléia Legislativa de Sergipe é o protótipo do modelo proposto no início dos anos 1990 por Fernando Abrucio. O achado mais interessante desse artigo é, certamente, que as demais assembléias têm, porém, características diferentes. Variáveis aqui tratadas como dominância, sucesso, conteúdo dos projetos, vetos, mostraram claramente esse ponto. Decerto, essa consideração deve ser feita cum grano salis em virtude do número limitado de legislaturas

23 Essa legislação faz parte de um arcabouço na qual as entidades assim reconhecidas são complementares à ação do Estado. No caso, as entidades que possuem o título de utilidade pública podem concorrer para obter pequenas transferências ou "convênios" que transferem recursos orçamentários estaduais e municipais. consideradas no estudo. Mas há elementos para acreditar que a dinâmica legislativa estadual seja um pouco mais complexa daquela inicialmente imaginada. Resta agora aberto o campo para tentar ampliar o conhecimento sobre as assembléias estaduais e, de certa forma, preencher a lacuna que ainda domina na Ciência Política no que tange o estudo das instituições representativas locais brasileiras. Questionamentos relevantes à compreensão da produção legislativa estadual brasileira recente e proposições normativas sobre a dinâmica desse processo político continuam a merecer hipóteses explicativas mais robustas. Com vista nisso, partindo dos achados apresentados nesse texto, sugerimos alguns possíveis caminhos para investigações futuras na esperança de que os estudos sobre as assembléias estaduais tornem-se mais proeminentes.

Em primeiro lugar o problema da agenda do poder Executivo e do poder Legislativo. É claro que a dinâmica legislativa das assembléias estaduais depende dos recursos que os atores políticos podem administrar. Mostramos que a liberdade constitucionalmente limitada quanto ao escopo normativo estadual que o poder Executivo tem na definição de sua agenda o torna um administrador local com fortes poderes "proativos" e poderosas prerrogativas legislativas, independentemente da base de apoio parlamentar. Essa consideração foi feita levando em conta o exame da legislação ordinária. Outros estudos deveriam buscar evidências no processo orçamentário em que, talvez, o domínio do Governador seja mais limitado e decorrente das variações no apoio dado pela sua base parlamentar. No que tange aos deputados estaduais, a pesquisa mostrou que há espaço para a organização de uma agenda pública mais complexa. O volume de propostas apresentadas pelos deputados de cunho estadual sinaliza para uma agenda pelo menos "desejada", principalmente direcionada a definir normas e diretrizes das políticas públicas estaduais. Fato que, é bom notar, foi observado em alguns estados onde as leis de caráter estadual representam uma categoria expressiva das normas sancionadas. $\mathrm{O}$ fato de que esse tipo de norma esconde na verdade uma série de benefícios concedidos para grupos organizados deve alertar-nos para a importância de futuras investigações em torno da relação entre políticos e parte do eleitorado mais organizado, como sindicados, associações, representações de categorias, grupos de pressão. 
Em segundo lugar, o problema da produção legislativa dos deputados à luz da teoria da conexão eleitoral; uma das teses mais exploradas na academia quando se investiga o Congresso Nacional. Aqui chamamos a atenção para a prática da apresentação por parte dos deputados de propostas cujo conteúdo é geograficamente limitado, em que os legisladores jogam autonomamente, com o resultado sendo mais dependente da barganha intraparlamentar. Neste trabalho, mostramos que o nível das leis denominadas "municipais" é expressivo. Assim, é lícito perguntarmo-nos: será que, por exemplo, as concessões de utilidades públicas seguem uma estratégia que vê o político envolvido em questões paroquiais para que isso se traduza em benefícios eleitorais tangíveis? O volume das normas municipais aprovadas no âmbito estadual ao lado das variações entre os 12 estados investigados é um laboratório promissor para o teste da teoria da conexão eleitoral que deveria ser explorado em pesquisas futuras.

Uma terceira e última consideração é feita no que tange o papel dos partidos políticos ou, mais em geral, do sistema partidário estadual. Apesar de o arcabouço institucional brasileiro limitar a ação dos deputados estaduais e, de certa forma, dos próprios partidos, isso não significa anular o processo de diferenciação que se dá em perspectiva partidária. Como também apontado em outros estudos comparativos, os sistemas políticos subnacionais diferem entre si com relação à lógica da relação Executivo-Legislativo, do sistema partidário e da formação de coalizões (SOUZA \& DANTAS NETO, 2006). Ou seja, há indícios claros de que nas assembléias estaduais algumas questões devem ser compreendidas à luz da clara contraposição entre governo e oposição. Por um lado, a diminuição, em alguns estados, da taxa de sucesso no último ano de governo mostra certa limitação na capacidade legislativa dos governadores. Já que seus poderes formais mantêm-se constantes durante a legislatura, é de esperar-se que outros fatores expliquem esse feito. Por outro lado, a prática dos vetos demonstra que a relação entre governo e poder legislativo deveria ser melhor aprofundada. Uma boa resposta é que a dimensão político-partidária pode melhor servir para explicar o comportamento dos atores. Assim, futuras pesquisas deverão ser feitas para melhor entender quanto à relação entre os atores políticos possa explicar o formato da produção legislativa de cada assembléia.

Fabrício Ricardo de Limas Tomio (fab_tom@hotmail.com) é Doutor em Ciência Política pela Universidade Estadual de Campinas (Unicamp) e Professor de Ciência Política no Departamento de Direito Público da Universidade Federal do Paraná (UFPR).

Paolo Ricci (paolo.ricci@terra.com.br) é Doutor em Ciência Política pela Universidade de São Paulo (USP) e Professor de Ciência Política na mesma universidade.

\section{REFERÊNCIAS BIBLIOGRÁFICAS}

ABRUCIO, F. 1998. Os barões da federação: os governadores e a redemocratização brasileira. São Paulo: Hucitec.

ABRUCIO, F.; CARVALHO TEIXEIRA, M. A. \& COSTA, V. M. F. 2001. O papel institucional da Assembléia Legislativa paulista: 1995 a 1998. In: SANTOS, F. (org.). O poder legislativo nos estados: diversidade e convergência. Rio de Janeiro: Fundação Getúlio Vargas.

AMES, B. 1995a. Electoral Strategy under OpenList Proportional Representation. American
Journal of Political Science, Bloomington, v. 39, n. 2, p. 406-433. Disponível em: http:// citeseerx.ist.psu.edu/viewdoc/ download; jsessionid=65 A 8 D 2 E 12BD7D53D0999C5A976E0DFCD?doi= 10.1.1.199.1454\& rep=rep1\& type $=$ pdf. Acesso em: 8.dez.2011

1995b. Electoral Rules, Constituency Pressure, and Pork Barrel: Bases of Voting in the Brazilian Congress. Journal of Politics, Statesboro, v. 57, n. 2, p. 324-343.

2001. Institutions and Politics in Bra-zil. Ann Arbor: University of Michigan. 
AMORIM NETO, O. \& SANTOS, F. 2003. O segredo ineficiente revisto: o que propõem e o que aprovam os deputados brasileiros. Dados, Rio de Janeiro, v. 46, n. 4, p. 661699. Disponível em: http://www.scielo.br/pdf/ dados/v46n4/a02v46n4.pdf. Acesso em: 8.dez.2011.

ANASTÁSIA, F. 2001. Transformando o Legislativo: a experiência da Assembléia Legislativa de Minas Gerais. In: SANTOS, F. (org.). O poder Legislativo nos estados: diversidade e convergência. Rio de Janeiro: Fundação Getúlio Vargas.

ARRETCHE, M. 2009. Continuidades e descontinuidades da Federação Brasileira: de como 1988 facilitou 1995. Dados, Rio de Janeiro, v. 52, n. 2, p. 377-423. Disponível em: http://www.scielo.br/pdf/dados/v52n2/ v52n2a04.pdf. Acesso em: 8.dez.2011.

BRAGA, S. 2007a. Podem as novas tecnologias de informação e comunicação auxiliar na consolidação das democracias? Um estudo sobre a informatização dos órgãos legislativos na América do Sul. Opinião Pública, São Paulo, v. 13, n. 1, p. 1-50, jun. Disponível em: http://www.scielo.br/pdf/op/v13n1/ v13n1a01.pdf. Acesso em: 8.dez.2011.

2007b. A informatização dos legislativos brasileiros no inicio da $16^{\mathrm{a}}$ legislatura. Teoria $\&$ Sociedade, Belo Horizonte, v. 14, p. 25-54, jul.-dez.

2008. As relações entre o Executivo e o Legislativo e a elaboração da política econômica na primeira experiência de democracia presidencialista pluripartidária brasileira (1946-1964). Campinas. Tese (Doutorado em Desenvolvimento Econômico). Universidade Estadual de Campinas.

BRAGA, S. \& FRANÇA, A. S. 2008. Produção legal e relação entre Executivo e Legislativo no Paraná (1999-2002). In: PERISSINOTTO M.; CODATO A.; BRAGA S. \& FUCKS, M. (orgs.). Quem governa? Um estudo das elites políticas do Paraná. Curitiba: UFPR.

CARREIRÃO, Y. S. \& PERONDI, E. 2009. Disciplina e coalizões partidárias na Assembléia Legislativa de Santa Catarina (1999-2006). Revista Brasileira de Ciências
Sociais, São Paulo, v. 24, n. 71, p. 121-141, out. Disponível em: http://www.scielo.br/pdf/ rbcsoc/v24n71/v24n71a09.pdf. Acesso em: 8.dez.2011.

CARVALHO, N. R. 2003. E no inicio eram as bases. Geografia política do voto e comportamento legislativo no Brasil. Rio de Janeiro: Revan.

CASTRO, M. M.; ANASTÁSIA, F. \& NUNES, F. 2009. Determinantes do comportamento particularista de legisladores estaduais brasileiros. Dados, Rio de Janeiro, v. 52, n. 4, p. 961-1001. Disponível em: http:// www.scielo.br/pdf/dados/v $52 \mathrm{n} 4 /$ v52n4a05.pdf. Acesso em: 8.dez.2011.

CER VI, E. U. 2009. Produção legislativa e conexão eleitoral na Assembléia Legislativa do estado do Paraná. Revista de Sociologia e Política, Curitiba, v. 17, n. 32, p. 159-185, fev. Disponível em: http://www.scielo.br/pdf/ rsocp/v17n32/v17n32a10.pdf. Acesso em: 8.dez.2011.

DOMINGUES, M. P. 2001. Espírito Santo: produção legal e relações entre os poderes Executivo e legislativo entre 1995 e 1998. In: SANTOS, F. (org.). O poder legislativo nos estados: diversidade e convergência. Rio de Janeiro: Fundação Getúlio Vargas.

FIGUEIREDO, A. \& LIMONGI, F. 2007. Instituições políticas e governabilidade. Desempenho do governo e apoio legislativo na democracia brasileira. In: MELO, C. R. \& SAEZ, M. A. A democracia brasileira: balanço e perspectivas para o século 21. Belo Horizonte: UFMG.

GAMM, G. \& KOUSSER, T. 2010. Broad Bills or Particularistic Policy? Historical Patterns in American State Legislatures. American Political Science Review, Los Angeles, v. 104, n. 1, 151-170, Feb. Disponível em: http:// www.stanford.edu/group/west/docs/ GammKousserpaper.pdf. Acesso em: 8.dez.2011.

GROHMANN, L. G. M. 2001. O processo legislativo no Rio Grande do Sul: 1995 a 1998. In: SANTOS, F. (org.). O poder Legislativo nos estados: diversidade e convergência. Rio de Janeiro: Fundação Getúlio Vargas. 
LEITE, A. A. \& SANTOS, M. L. 2010. Voto, parlamento e políticas públicas. Instituições Políticas em Pernambuco. Recife: UFPE.

LEMOS, L. B. S. 2001. O Congresso Brasileiro e a distribuição de benefícios sociais no período 1988-1994: uma análise distributivista. Dados, Rio de Janeiro, v. 44, n. 3, p. 561-605. Disponível em: http://www.scielo.br/pdf/ dados/v44n3/a04v44n3.pdf. Acesso em: 8.dez.2011.

LEMOS, L. \& RICCI, P. 2011. Individualismo e partidarismo na lógica parlamentar: o antes e o depois das eleições. In: POWER, T. \& ZUCCO, C. (orgs.). O Congresso por ele mesmo: autopercepções da classe política brasileira. Belo Horizonte: UFMG.

LIMONGI, F. 2006. A democracia no Brasil. Presidencialismo, coalizão partidária e processo decisório. Novos Estudos, São Paulo, v. 76, p. 17-41, nov. Disponível em: http:// www.scielo.br/pdf/nec/n76/02.pdf. Acesso em: 8.dez.2011.

LOWENBERG, G. \& PATTERSON, S. 1979. Comparing Legislatures. Boston: Little Brown.

MAINWARING, S. 1999. Rethinking Party Systems in the Third Wave of Democratization. The Case of Brazil. Stanford: Stanford University.

MORAES, F. 2001. A dinâmica legislativa na Assembléia do Estado do Ceará: 1995 a 1998, In: SANTOS F. (org.). O poder Legislativo nos estados: diversidade e convergência. Rio de Janeiro: Fundação Getúlio Vargas.

NUNES, F. 2008a. Convergência partidária e base parlamentar: o comportamento dos partidos na Assembléia Legislativa de Minas Gerais entre 1995 e 2005. Cadernos da Escola do Legislativo, Belo Horizonte, v. 10, n. 15, p. 83-130, jan.-dez. Disponível em: http:// www.almg.gov.br/opencms/export/sites/ default/consulte/publicacoes_assembleia/ periodicas/cadernos/arquivos/pdfs/15/ Felipe.pdf. Acesso em: 8.dez.2011.

2008b. Governos de coalizão e resul-tados de soma positiva em Minas Gerais e Rio Grande do Sul, 1999-2006. Belo Horizonte. Dissertação (Mestrado em Ciência Política). Universidade Federal de Minas Gerais.
2009. Qual a estratégia mais eficiente para obter apoio parlamentar? A relação Executivo-Legislativo em 12 assembléias estaduais. Trabalho apresentado no Encontro da International Political Science Association (IPSA), Santiago, digit.

OLIVEIRA, V. E. 2009. Poder Judiciário: árbitro dos conflitos constitucionais entre estados e união. Lua Nova, São Paulo, v. 78, n. 3, p. 223-250. Disponível em: http://www.scielo.br/ pdf/ln/n78/a11n78.pdf. Acesso em: 8.dez.2011.

PEREIRA, A. 2001. Sob a ótica da delegação: governadores e assembléias no Brasil pós1989, In: SANTOS F. (org.) O poder Legislativo nos estados: diversidade e convergência. Rio de Janeiro: Fundação Getúlio Vargas.

RICCI, P. 2002. A medida das leis: o uso de noções genéricas à mensuração do imponderável. Revista Brasileira de Informação Bibliográfica em Ciências Sociais, São Paulo, v. 54, p. 101-123, $2^{\circ}$ semestre.

2003. O conteúdo da produção legislativa brasileira: leis nacionais ou políticas paroquiais? Dados, Rio de Janeiro, v. 46, n. 4, p. 699-734. Disponível em: http:// www.scielo.br/pdf/rbcsoc/v19n55/ a07v1955.pdf. Acesso em: 8.dez.2011.

2010. The Content of Law. Concepts and Measures in Legislative Studies. The Committee on Concepts and Methods Working Paper Series, Ciudad del Mexico, n. 43. Disponível em: http://www.concepts-methods.org/ WorkingPapers/PDF/1071. Acesso em: 8.dez.2011.

SAMUELS, D. 2000. Concurrent Elections, Discordant Results: Presidentialism, Federalism, and Governance in Brazil. The Journal of Comparative Politics, New York, v. 33, n.1, p. 1-20. Disponível em: http:// www.polisci.umn.edu/ d samuels/ CP2000.pdf. Acesso em: 8.dez.2011.

SANTOS, F. 1995. Microfundamentos do clientelismo político no Brasil: 19591963. Dados, Rio de Janeiro, v. 38, n. 3, p. 459-496.

2001a. A dinâmica Legislativo no estado do Rio de Janeiro: análise de uma legislatura. 
In:

. (org.) O poder Legislativo nos estados: diversidade e convergência. Rio de Janeiro: Fundação Getúlio Vargas.

(org.) 2001b. O poder legislativo nos estados: diversidade e convergência. Rio de Janeiro: Fundação Getúlio Vargas.

SOUZA, C. 2005. Federalismo, desenho constitucional e instituições federativas no brasil pós-1988. Revista de Sociologia e Politica, v. 24, p. 105-121.

SOUZA, C. \& DANTAS NETO, P. F. 2006. Governo, elites políticas e politicas públicas nos estados brasileiros. Rio de Janeiro: Revan.

SHUGART, M. \& CAREY, J. 1992. Presidents and Assemblies: Constitutional Design and Electoral Dynamics. Cambridge: Cambridge University.

TOMIO, F. R. L. 2002. A criação de municípios após a Constituição de 1988. A Criação de municípios após a Constituição de 1988. Revista Brasileira de Ciências Sociais, São
Paulo, v. 17, n. 48, p. 61-89, fev. Disponível em: http://www.scielo.br/pdf/rbcsoc/v17n48/ 13950.pdf. Acesso em: 8.dez.2011.

2005a Autonomia municipal e criação de governos locais: a peculiaridade institucional brasileira. Revista da Faculdade de Direito, Curitiba, v. 42, p. 103-120. Disponível em: http://ojs.c3sl.ufpr.br/ojs2/index.php/direito/ article/view/5178/3894. Acesso em: 8.dez.2011.

2005b. Federalismo, municípios e decisões legislativas: a criação de municípios no Rio Grande do Sul. Revista de Sociologia e Política, Curitiba, v. 24, p. 123-148. Disponível em: http://www.scielo.br/pdf/ rsocp/n24/a09n24.pdf. Acesso em: 8.dez.2011.

2006. Medidas provisórias, iniciativas e decisões legislativas no processo decisório estadual catarinense. In: CARREIRÃO, Y. \& BORBA, J. Os partidos na política catarinense: eleições, processo legislativo, políticas públicas. Florianópolis: Insular. 


\section{APÊNDICE}

\section{NOTAS SOBRE A COLETA E A ORGANIZAÇÃO DOS DADOS}

As 12 assembléias estaduais que foram estudadas são as seguintes: Alagoas, Amapá, Ceará, espírito Santo, Minas Gerais, Paraíba, Paraná, Rio de Janeiro, Rio Grande do Sul, Santa Catarina, São Paulo e Sergipe. A coleta das informações sobre a legislação estadual sofre de inúmeras limitações e dificuldades operacionais. A principal delas é o fato de que apenas recentemente as assembléias disponibilizam online bases de informações consolidadas. No âmbito subnacional, diferentemente da Câmara dos Deputados e do Senado Federal que demonstram alto grau de informatização (BRAGA, 2007a), há diferenças significativas entre os estados quanto ao acesso aos dados primários (BRAGA, 2007b). Isso poderia gerar um possível viés de seleção caso analisassem-se apenas os estados com capacidade de disponibilizar melhor suas informações. Para não introduzir um viés de seleção no estudo optouse por analisar não apenas os estados cujo nível de informatização é mais elevado e o acesso aos dados é mais facilitado (como Minas Gerais, São
Paulo, Rio Grande do Sul, Espírito Santo e Santa Catarina), mas também os estados onde o levantamento das informações era mais difícil (como em Alagoas, Sergipe, Paraíba, Paraná e Ceará). Nesse último caso a pesquisa foi realizada in loco e os dados foram consolidados diretamente nos arquivos e bases de dados das assembléias legislativas, dada a precariedade ou inexistência das informações fornecidas pelos sítios oficiais.

A dificuldade de coleta dos dados tornou viável o exercício comparativo da produção legislativa das assembléias estaduais para as duas últimas legislaturas (1999-2002; 2003-2006), com a exceção dos estados de Alagoas, Paraíba e Sergipe, pelos quais não obtivemos dados completos para a legislatura 1999-2002. A organização de uma base de dados eletrônica com o processo legislativo das duas legislaturas investigadas tem um total de 45 576 projetos de leis. A Tabela 7 a seguir mostra o volume dos projetos distinguindo-os por tipo de normas.

TABELA 7 - TIPOS DE PROPOSIÇÕES LEGISLATIVAS, APRESENTADAS E APROVADAS

\begin{tabular}{|l|c|c|}
\hline TIPO DE LEI & APRESENTADAS & APROVADAS \\
\hline Projetos de Emendas Constitucionais (PEC) & 973 & 221 \\
Projetos de Leis Complementar (PLC) & $(2,2)$ & $(1,0)$ \\
& 1639 & 779 \\
Medidas Provisórias (MP) & $(3,7)$ & $(3,6)$ \\
& 102 & 73 \\
Projetos de Lei Ordinários (PL) de natureza & $(0,2)$ & $(0,3)$ \\
administrativa -orçamentária & 12493 & 6667 \\
Outros Projetos de Lei Ordinários (PL) & $(28)$ & $(30)$ \\
& 29488 & 14512 \\
Total & $(65,9)$ & $(65,1)$ \\
& $44695^{1}$ & $22287^{2}$ \\
\hline
\end{tabular}

FONTE: Os autores.

NOTAS:

1. Novecentos e cinquenta e dois missing para a categoria de projetos de natureza administrativaorçamentária e para os projetos ordinários;

2. Mil duzentos e oitenta e oito missing. 
Nota-se que as Propostas de Emendas à Constituição (PEC), os Projetos de Lei Complementar (PLC) e as Medidas Provisórias (MP) não são preponderantes e, conjuntamente, somam $5,7 \%$ das propostas apresentadas e $4,8 \%$ das aprovadas. No caso das PECs, os estados seguem os princípios expressos na Constituição Federal, sendo a iniciativa legislativa bastante restrita e o quorum qualificado para aprovação elevado. O caso das MPs é interessante. Esse instrumento legal é previsto apenas no caso do Acre, Paraíba, Maranhão, Piauí, Santa Catarina e Tocantins. O escopo das MPs estaduais é, porém, diferente daquele federal. Nesse último caso, as MPs conferem ao Presidente ampla preponderância no processo decisório. Suas determinações, combinadas a outros mecanismos (prerrogativas dos lideres, disciplina partidária, coalizão majoritária etc.) atribuíram uma preponderância do poder Executivo no processo decisório. Entretanto, nos estados, esse mecanis- mo não parece ter o mesmo desempenho. O escopo das MPs estaduais é, institucionalmente, muito restrito. Assim como as atribuições dos poder executivos estaduais são bem mais limitadas - comparadas às definidas ao poder Executivo federal -, já que não elaboram planos de estabilização econômica, por exemplo. Portanto, essa prerrogativa possui menor relevância institucional de seus efeitos jurídicos. Dos 12 estados estudados, apenas Santa Catarina e Paraíba prevêem esse mecanismo. Como se pode notar, o volume de MPs é baixo. $\mathrm{O}$ fato de a legislação "superior", que exige quorum qualificado (PEC e PLC), ser pouco numerosa, quando comparada ao conjunto da produção legislativa "ordinária" observada, fez que deixássemos de lado a diferenciação entre normas desse tipo e considerássemos "apenas" a distinção clássica entre normas originadas nos poderes Executivo, Legislativo e as do Judiciário e outros (Ministério Público, Tribunal de Contas e Procuradoria). 


\section{THE STATE GOVERNMENT IN BRAZILIAN POLITICAL EXPERIENCE: LEGISLATIVE PERFORMANCE IN STATE ASSEMBLIES}

\section{Fabrício Ricardo de Limas Tomio and Paolo Ricci}

This article analyzes the legislative process and performance in 12 Brazilian state legislative assemblies during two legislative periods (1999-2002 and 2002-2006). Our initial goal was to provide a perspective on the volume and dynamics of legislative production through identification of determining aspects of decision-making processes and analysis of certain indicators, such as the volume of the projects presented and the success rate of bills and vetoes. We also look at the content of the proposals presented by governors and state representatives, using this variation to problematize the state legislative process. As a result, some interpretative considerations can be made. Thus, in the first place we see that the legislative dynamic of state assemblies depends on the institutional resources that are constitutionally conferred upon political actors by the Federal Constitution, which in turn restricts the legislation that state representatives are able to propose and limits governor's legislative autonomy. Yet this does not annul the differentiation process that springs from different political party perspectives. Rather, we have a clear indication that political party dynamics and effective interaction between government and opposition within assemblies explain the variation encountered between states. In the second place, our data show that there is a diversified state legislative dynamic that is not annulled by Executive power. The volume of proposals presented by state representatives that do not distribute concentrated benefits are an indication of a "desired" agenda, geared primarily toward defining norms and directives of state public policy.. Yet at the same time, we see that although the legislative success of state representatives is high when compared to that of federal representatives, it is basically limited to one type of norm: concession of concentrated benefits, among which public utility declarations stand out. Our research efforts and the data presented here should call attention to the need for future research on state assemblies, seeking a better understanding of the way Brazilian institutions work within the sub-national ambit.

KEYWORDS: Legislative Process; Legislative Assembly; Executive-Legislative Relations; Political Institutions. 